UNIVERSIDADE DE SÃO PAULO

ESCOLA DE EDUCAÇÃO FÍSICA E ESPORTE

\title{
INFLUÊNCIA DA ORIENTAÇÃO ESPACIAL E DO CONTROLE POSTURAL NA LOCOMOÇÃO DE IDOSOS
}

\author{
Renata Garrido Cosme
}

São Paulo

2009 
INFLUÊNCIA DA ORIENTAÇÃO ESPACIAL E DO CONTROLE POSTURAL NA LOCOMOÇÃO DE IDOSOS

RENATA GARRIDO COSME

Dissertação apresentada à Escola de Educação Física e Esporte da Universidade de São Paulo, como requisito parcial para obtenção do grau de Mestre em Educação Física.

ORIENTADOR: PROF.DR. LUIS MOCHIZUKI 


\section{AGRADECIMENTOS}

Agradeço às Instituições que apoiaram este trabalho: à Universidade de São Paulo, à Escola de Educação Física e Esporte, à Coordenação de Aperfeiçoamento de Pessoal de Nível Superior (CAPES).

Ao Prof. Dr. Luis Mochizuki agradeço pela formação e pela amizade construída ao longo desses oito anos de convivência. Por me acolher na decisão de entrar no Laboratório de Biomecânica para fazer minha Iniciação Científica, quando era apenas uma aluna da graduação, e, continuar sendo meu guia durante meu mestrado. É sem dúvida um grande orientador.

Ao Prof. Julio Cerca Serrão agradeço pelas lições e pela oportunidade que me abriu ao permitir que eu fizesse parte de seu grupo.

Aos amigos do Laboratório de Biomecânica da EEFE agradeço pela amizade e ajuda, construímos uma família. Em especial agradeço à Jaqueline, quem sempre me ajudou, principalmente nas incompatibilidades computacionais...

Às minhas queridas amigas da Universidade São Judas Tadeu, Aline, Flávia, Patrícia, somos realmente um grupo.

Aos meus pais e minha irmã agradeço pelo carinho e por me compreenderem todas as vezes que fiquei estressada e fui ausente.

Ao Fernando, amor da minha vida, agradeço pelo apoio e por compreender todas as vezes que deixei de estar ao seu lado.

Aos meus amigos agradeço pelos momentos de risos.

Agradeço a mim, sem minha dedicação e persistência nada seria possível. 


\section{SUMÁRIO}

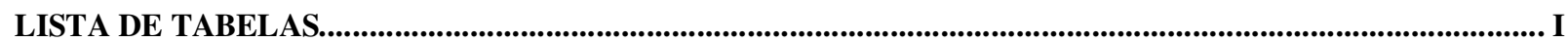

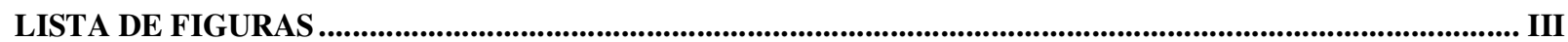

LISTA DE SIGLAS, ABREVIAÇÕES E SÍMBOLOS ......................................................................................

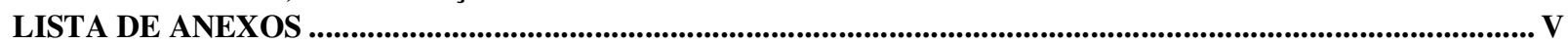

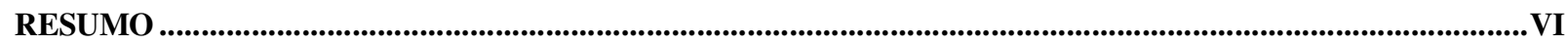

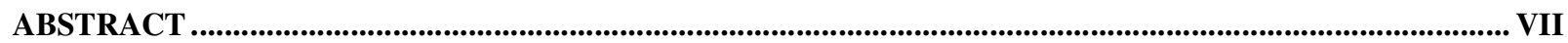

1 INTRODUÇÃ

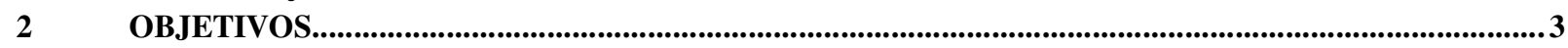



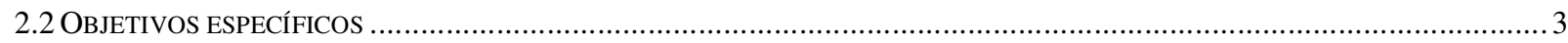

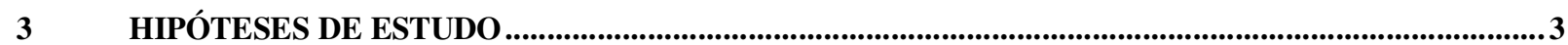

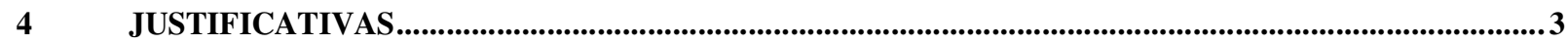

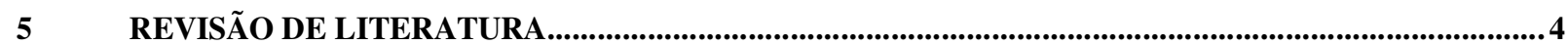

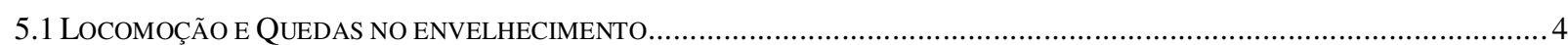

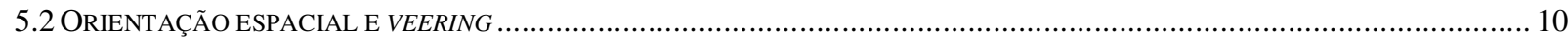

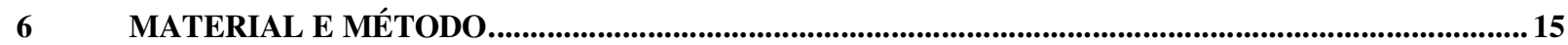

6.1 SOBRE OS PROCEDIMENTOS ÉTICOS PARA DESENVOLVIMENTO DO PROJETO DE PESQUISA....................................... 15

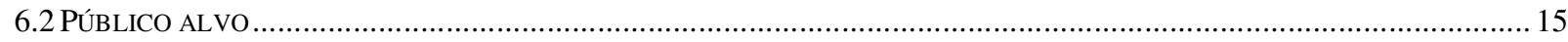

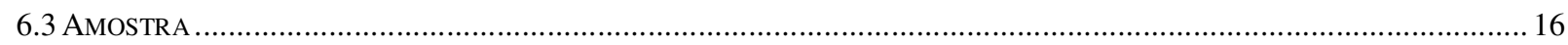

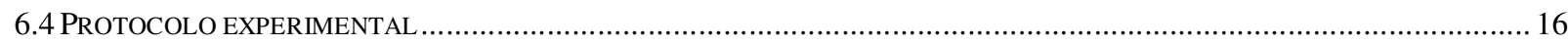

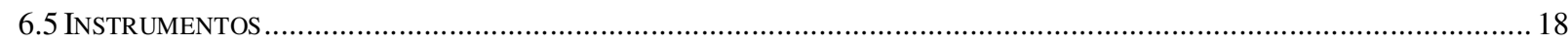

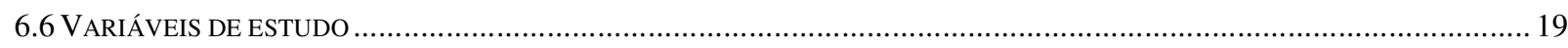

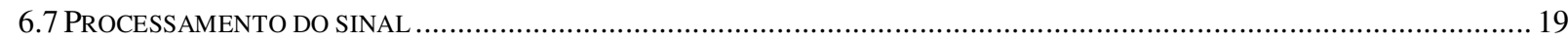

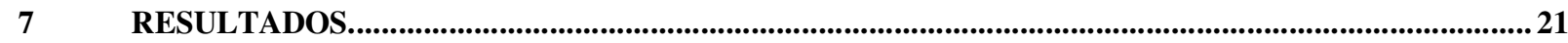

7.1 EFEITO DO GRUPO NOS TESTES DE RISCO DE QUEDAS E NO DESVIO DA DIREÇÃO...............................................2

7.2 EFEITO DOS FATORES DE RISCO DE QUEDAS NOS TESTES DE RISCO DE QUEDAS E NO DESVIO DA DIREÇÃO ..................23

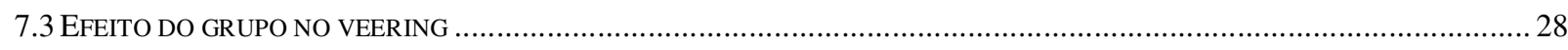

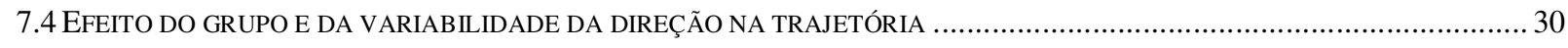

7.5 EFEITO DOS TESTES DE RISCO DE QUEDAS NA VARIABILIDADE DA DIREÇÃO DA TRAJETÓRIA …................................ 32

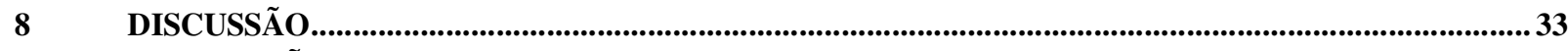

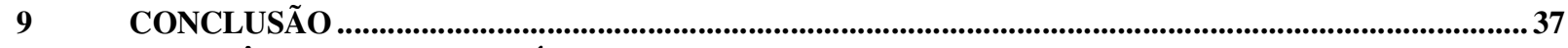

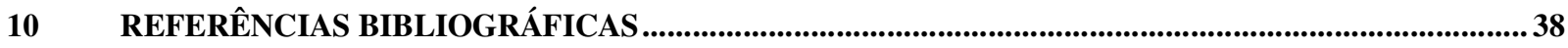




\section{LISTA DE TABELAS}

TABELA 1: Valores médios e desvio padrão do teste Berg de equilíbrio para os grupos: idoso atividade física (idoso AF), idoso risco de quedas (idoso RQ) e adulto.

TABELA 2: Valores médios e desvio padrão do teste Tinetti para equilíbrio sentado, equilíbrio em pé, equilíbrio total, marcha, escore total para os grupos: idoso atividade física (idoso AF), idoso risco de quedas (idoso RQ) e adulto.

TABELA 3: Valores médios e desvio padrão do desvio e variabilidade do teste de orientação espacial de olhos fechados para os grupos idoso atividade física (idoso AF), idoso risco de quedas (idoso $\mathrm{RQ}$ ), adulto. Os valores positivos indicam o desvio para a direita e os valores negativos o desvio para a esquerda.

TABELA 4: Valores médios e desvio padrão do teste Berg de equilíbrio dos sujeitos sem antecedente de queda (não) e dos sujeitos com antecedente de queda (sim).

TABELA 5: Valores médios e desvio padrão do teste Tinetti para equilíbrio sentado, equilíbrio em pé, equilíbrio total, marcha, escore total dos sujeitos sem antecedente de queda (não) e dos sujeitos com antecedente de queda (sim).

TABELA 6: Valores médios e desvio padrão do desvio e sua variabilidade do teste de orientação espacial de olhos fechados dos sujeitos com (sim) e sem antecedente de queda (não). Os valores positivos indicam o desvio para a direita e os valores negativos o desvio para a esquerda.

TABELA 7: Valores médios e desvio padrão do teste Berg de equilíbrio dos sujeitos com (sim) e sem problemas de visão (não).

TABELA 8: Valores médios e desvio padrão do teste Tinetti para equilíbrio sentado, equilíbrio em pé, equilíbrio total, marcha, escore total dos sujeitos com problemas de visão (sim) e dos sujeitos sem problemas de visão (não)

TABELA 9: Desvio médio e variabilidade do teste de orientação espacial de olhos fechados dos sujeitos com (sim) e sem problemas de visão (não). Os valores positivos indicam o desvio para a direita e os valores negativos o desvio para a esquerda.

TABELA 10: Valores médios e desvio padrão do teste Berg de equilíbrio dos sujeitos sem labirintite (não) e com labirintite $(\operatorname{sim})$.

TABELA 11: Valores médios e desvio padrão do teste Tinetti para equilíbrio sentado, equilíbrio em pé, equilíbrio total, marcha, escore total dos sujeitos sem labirintite (não) e com labirintite (sim). ....... 26

TABELA 12: Desvio médio e variabilidade do teste de orientação espacial de olhos fechados dos sujeitos sem labirintite (não) e com labirintite (sim). Os valores positivos indicam o desvio para a direita. . 26

TABELA 13: Valores médios e desvio padrão do teste Berg de equilíbrio de acordo com a ingestão diária 
de medicamentos: nada, pouco (até 3 comprimidos) e risco (4 ou mais comprimidos).

TABELA 14: Valores médios e desvio padrão do teste Tinetti para equilíbrio sentado, equilíbrio em pé, equilíbrio total, marcha, escore total de acordo com a ingestão diária de remédio: nada, pouco (até 3 comprimidos), risco (4 ou mais comprimidos).

TABELA 15: Desvio médio e variabilidade do teste de orientação espacial de olhos fechados de acordo com a ingestão diária de medicamentos: nada, pouco (até 3 comprimidos), risco (4 ou mais comprimidos). Os valores positivos indicam o desvio para a direita e os negativos o desvio para a esquerda.

TABELA 16: Valores médios e desvio padrão do teste Berg de equilíbrio dos sujeitos de acordo com a lateralidade: destro, canhoto.

TABELA 17: Valores médios e desvio padrão do teste Tinetti para equilíbrio sentado, equilíbrio em pé, equilíbrio total, marcha, escore total dos sujeitos de acordo com a lateralidade destra ou canhota... 28

TABELA 18: Desvio médio e variabilidade do teste de orientação espacial de olhos fechados dos sujeitos destros e canhotos. Os valores positivos indicam o desvio para a direita.

TABELA 19: Valores médios e desvio padrão das medidas de erro absoluto, de erro variável, de erro constante, da média do ângulo do desvio e da variabilidade do ângulo do desvio (em graus) para os grupos: idoso atividade física (idoso AF), idoso risco de quedas (idoso RQ) e adulto.

TABELA 20: Valores médios e desvio padrão da direção do desvio do alvo em porcentagem (\%) para grupos: idoso atividade física (idoso $\mathrm{AF}$ ), idoso risco de quedas (idoso $\mathrm{RQ}$ ) e adulto.

TABELA 21: Valores médios e desvio padrão do expoente do DFA nas direções médio-lateral e ânteroposterior para grupos: idoso atividade física (idoso $\mathrm{AF}$ ), idoso risco de quedas (idoso RQ) e adulto.

TABELA 22: Valores médios e desvio padrão da dimensão fractal do DFA nas direções médio-lateral e ântero-posterior para grupos: idoso atividade física (idoso AF), idoso risco de quedas (idoso RQ) e adulto.

TABELA 23: Valores médios e desvio padrão do tempo crítico da análise do random walk nas direções médio-lateral e ântero-posterior para grupos: idoso atividade física (idoso $\mathrm{AF}$ ), idoso risco de quedas (idoso RQ) e adulto.

TABELA 24: Valores médios e desvio padrão da dimensão do componente curto e longo da análise do random walk nas direções médio-lateral (ML) e ântero-posterior (AP) para grupos: idoso atividade física (idoso AF), idoso risco de quedas (idoso RQ) e adulto.

TABELA 25: Valores médios e desvio padrão do coeficiente de Hurst do componente curto e longo da análise random walk nas direções médio-lateral (ML) e ântero-posterior (AP) para grupos: idoso atividade física (idoso $\mathrm{AF}$ ), idoso risco de quedas (idoso RQ) e adulto. 


\section{LISTA DE FIGURAS}

FIGURA 1 - Tarefa proposta: posiciona-se o indivíduo no início com os calcanhares alinhados em 90 com o aparato de madeira $(0,0)$, ao comando sonoro caminha em direção ao X, posição final $(0,15)$. A partir da diferença entre a trajetória pretendida (trajetória ideal) e a realizada (trajetória real) mensura- se o veering (desvio). A tarefa é realizada uma vez de olhos abertos e dez vezes de olhos

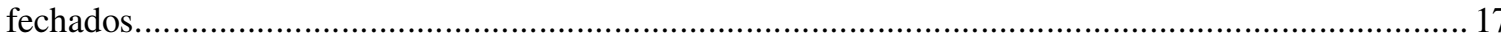

FIGURA 2 - Diagrama de blocos com descrição do protocolo experimental. ................................................. 18 


\section{LISTA DE SIGLAS, ABREVIAÇÕES E SÍMBOLOS}

$\mathrm{AF}$ - atividade física

$\mathrm{AP}$ - ântero- posterior

APA - ajuste postural antecipatório

APC - ajuste postural compensatório

COM - centro de massa

DFA - Detrend Flutuation Analysis

DLT - dimensão do componente longo do Random Walk Analysis

DST - dimensão do componente curto do Random Walk Analysis

HLT - coeficiente de Hurst do componente curto do Random Walk Analysis

HST - coeficiente de Hurst do componente curto do Random Walk Analysis

Idoso AF - idoso atividade física

Idoso RQ - idoso risco de quedas

IPAQ - International Physical Activity Questionnaire

ML - médio- lateral

n - número da amostra 


\section{LISTA DE ANEXOS}

Página



ANEXO 2- QUESTIONÁRIO DE AVALIAÇÃO DA CAPACIDADE FUNCIONAL .............................. 44

ANEXO 3- QUESTIONÁRIO DO NÍVEL DE ATIVIDADE FÍSICA IPAQ ............................................ 45

ANEXO 4- CLASSIFICAÇÃO DO NÍVEL DE ATIVIDADE FÍSICA IPAQ ........................................... 48

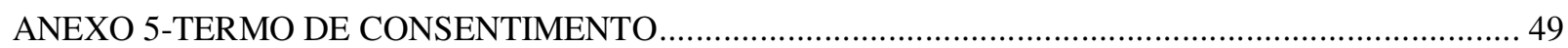





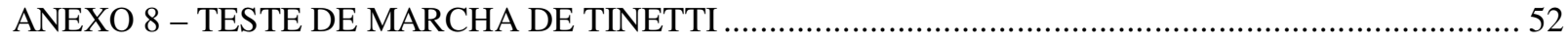

ANEXO 9 - ROTINA PARA CÁLCULO DO DFA E RANDOM WALK 1 ................................................ 53

ANEXO 10 - ROTINA PARA O CÁLCULO DO DFA E RANDOM WALK 2 ........................................ 54 


\title{
RESUMO
}

\section{INFLUÊNCIA DA ORIENTAÇÃO ESPACIAL E DO CONTROLE POSTURAL NA LOCOMOÇÃO DE IDOSOS}

\author{
Autor: RENATA GARRIDO COSME
}

Orientador: PROF. DR. LUIS MOCHIZUKI

\begin{abstract}
No andar, o risco de quedas em idosos é maior. O objetivo é estudar o risco de quedas na locomoção sem visão e a relação entre orientação espacial, veering e controle postural. Participaram 27 adultos

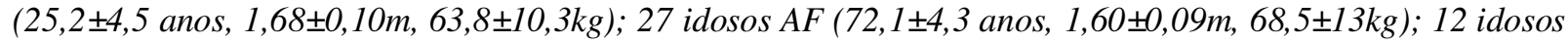
$R Q(72,3 \pm 6$ anos, $1,57 \pm 0,08 \mathrm{~m}, 67,4 \pm 10,9 \mathrm{~kg})$. Eles caminharam $15 \mathrm{~m}$ sem visão com um acelerômetro fixo entre L1 e L2. Variáveis: grupo; variabilidade do desvio; erro absoluto e variável; DFA; Tc; HST; DLT. O idoso $R Q$ teve maior variabilidade do desvio $\left(F_{(2,63)}=4,6, p=0,01\right)$, erro absoluto $\left(F_{(2,63)}=16,64, p<0,0001\right) e$ variável $\left(F_{(2,63)}=4,5, p=0,01\right)$. Grupo $\left(F_{(2,652)}=48,9, p<0,0001\right)$ e direção $\left(F_{(1,652)}=444,5, p<0,0001\right)$ afetaram o DFA, e foi maior nos idosos e em AP $(p<0,0001)$. O grupo $\left(F_{(2,652)}=29,3, p<0,0001\right)$ e direção $\left(F_{(1,652)}=605\right.$, $p<0,0001)$ afetaram o HST, no idoso $R Q$ e na $M L(p<0,0001)$. O grupo $\left(F_{(2,652)}=30,8, p<0,0001\right)$ e direção $\left(F_{(1,652)}=178, p<0,0001\right)$ afetaram HLT,que foi maior nos idosos e em $M L(p<0,0001)$. A forma como o indivíduo caminha nas direções $M L$ e AP são diferentes. $O$ controle da oscilação é anti-persistente na direção $M L$ e persistente na AP. Os idosos dependem mais da visão na estabilização ML na locomoção. Os idosos $R Q$ apresentam maior veering, os idosos AF e adultos têm veering semelhante. A AF pode retardar o envelhecimento quanto à estabilidade dinâmica e à memória espacial durante a locomoção sem visão, diminuindo o risco de quedas.
\end{abstract}

Palavras chaves: biomecânica, idosos, quedas, orientação espacial, veering, controle postural. 


\begin{abstract}
THE INFLUENCE OF SPATIAL ORIENTATION AND POSTURAL CONTROL DURING

ELDERLY LOCOMOTION
\end{abstract}

Author: RENATA GARRIDO COSME

Adviser: PROF.DR. LUIS MOCHIZUKI

For elderly, the risk to fall increases during walking. The aim of this project is to study the risk to fall in elderly during gait without vision and its relation to spatial orientation, veering and postural control. The subjects were 27 adults $(25.2 \pm 4.5$ years old, $1.68 \pm 0,10 \mathrm{~m}$ height, $63.8 \pm 10.3 \mathrm{~kg}$ weight $) ; 27$ elderly AF (72.1 \pm 4.3 years old, $1.60 \pm 0.09 \mathrm{~m}$ height, $68.5 \pm 13 \mathrm{~kg}$ weight $) ; 12$ elderly $R Q(72.3 \pm 6$ years old, $1.57 \pm 0.08 \mathrm{~m}$ height, $67.4 \pm 10.9 \mathrm{~kg}$ weight). The subjects were instructed to walk straight ahead with their eyes closed for $15 \mathrm{~m}$, with an accelerometer fixed between L1 and L2. The variables were: group; target variability; absolute and variable error; DFA; Tc; HST; DLT. The elderly $R Q$ showed the highest target variability $\left(F_{(2,63)}=4.6\right.$, $p=0.01)$, absolute $\left(F_{(2,63)}=16.6, p<0,0001\right)$ and variable error $\left(F_{(2,63)}=4.5, p=0.01\right)$. Group $\left(F_{(2,652)}=48.9\right.$, $p<0.0001)$ and direction $\left(F_{(1,652)}=444, p<0.0001\right)$ affected DFA, AP and elderly showed the highest values $(p<0.0001)$. Group $\left(F_{(2,652)}=29.3, p<0.0001\right)$ and direction $\left(F_{(1,652)}=605, p<0.0001\right)$ affected HST, elderly $R Q$ and $M L$ showed the highest values $(p<0.0001)$. Group $\left(F_{(2,652)}=30.8, p<0.0001\right)$ and direction $\left(F_{(1,652)}=178\right.$, $p<0.0001)$ affected HLT, all elderly and ML showed the highest values $(p<0.0001)$. The direction affects gait control, it is anti-persistent for ML direction and persistent for AP direction. The lack of visual information affects more the elderly in $M L$ direction. The elderly $R Q$ showed larger veering; while the others were similar. Physical activity may slow down the aging process by affecting the dynamic stability and spatial memory during gait without vision, leading to reduce the risk of fall.

Key words: biomechanics, elderly, fall, spatial orientation, veering, postural control 


\section{INTRODUÇÃO}

É inquestionável o crescimento da população idosa no mundo. A Organização Mundial da Saúde em 2001 avaliou em 1,2 bilhão o número de pessoas com mais de 60 anos em 2005, enquanto os idosos com mais de 80 anos constituiriam o grupo etário de maior crescimento. Deste grupo, 25\% vivem em países subdesenvolvidos ou em desenvolvimento (Sousa et al., 2003). Estima-se que o Brasil terá a sexta maior população idosa em 2020 (Schoueri et al, 1994), com 52 milhões em 2050 (IBGE, 2006), sendo 13,7 milhões com mais de 80 anos (IBGE, 2009). Hoje a população do Brasil é jovem; enquanto em 2050, será caracterizada como mais velha, majoritariamente com pessoas com mais de 40 anos e com expectativa de vida de 81,3 anos (IBGE, 2009).

O envelhecimento resulta de um processo biológico que provoca mudanças estruturais (Okuma, 1998) e funcionais que podem refletir mudanças nas condições psicológicas e sociais do indivíduo, afetando a relação com o meio (Salgado, 1980). Diante disso, cresce a preocupação em se estudar o envelhecimento e os eventos associados que ameaçam a qualidade de vida, como as quedas acidentais. Em idosos, as quedas tornam-se freqüentes e causam lesões, constituindo a sua principal causa de morte acidental. Cerca de 30\% das pessoas saudáveis com 65 anos caem pelo menos uma vez ao ano, 47\% nas pessoas entre 70 e 74 anos, e 94\% entre 80 e 84 anos (Cumming, 1998).

As causas das quedas em idosos são variadas. Os fatores responsáveis são intrínsecos, que decorrem de alterações como o surgimento de doenças que ocasionem redução da capacidade física comprometendo o controle postural, força muscular, velocidade da marcha, equilíbrio, flexibilidade, tempo de reação e de movimento; ou extrínsecos, que dependem de circunstâncias sociais e ambientais (Berg et al., 1997). A queda resulta do desequilíbrio (vertigem, tontura, desmaio, superfícies irregulares) ou da inabilidade de corrigir desequilíbrios (Spirduso, 1995). A diminuição da coordenação motora na velhice provoca a redução da velocidade dos movimentos, coordenação e qualidade de execução de atos motores, refletindo na falta de reação às situações inesperadas como as quedas (Weineck, 1991). A ocorrência de uma queda anterior, a deficiência cognitiva e funcional e o uso de medicamentos psicotrópicos podem reincidir a queda (Gama et al, 2008; Coutinho et al., 2002; Kelly et al., 2003).

No andar, o risco de quedas em idosos é maior (Kesler et al, 2005) pois exige a coordenação de muitos músculos e articulações em equilíbrio dinâmico, sendo considerada uma tarefa complexa (Hausdorff et al, 2005) com exigências cognitivas associadas à ação, percepção e postura (Cook, Woollacott, 2003). Para reduzir o risco de quedas, surgem adaptações como menor comprimento da passada e velocidade da marcha, maior tempo de duplo apoio na locomoção de idosos (Cook, Woollacott, 2003; Warren, Wertheim, 1990; Brooks, 1986; MCardle, Katch, Katch, 1998; Shephard, 1997; Spirduso, 1995; Weinck, 1991).

O declínio da estabilidade postural na ausência da informação visual inicia-se aos 40 anos (Choy et al, 2003).Com a ausência da informação visual o corpo humano muda seu comportamento normal, apresentando maior balanço postural (Harwood, 2001), maior tempo para a estabilização do corpo frente a uma perturbação 
externa e, modificando o uso das sinergias neuromusculares (Cosme et al., 2004). O aumento da instabilidade e dependência da visão é proporcional ao risco de quedas (Harwood, 2001). A menor estabilidade pode influenciar o padrão da marcha. Idosos tendem a caminhar mais devagar no escuro e, aqueles que possuem alteração na marcha tendem a ficar mais instáveis no escuro (Kesler et al., 2005).

A percepção para a localização e a orientação do corpo no espaço independente da visão é chamada de orientação espacial cinestésica (Haywood \& Getchell, 2004). A informação visual é fundamental para a orientação do indivíduo, e na ausência, o indivíduo não mantém o deslocamento sem desvios (Vuillerme et al., 2002). Quando caminhamos com os olhos abertos, confrontamos a trajetória observada com a trajetória virtual contruída mentalmente. Desta forma, o controle da locomoção requer a representação dinâmica da relação entre corpo e ambiente (Berthoz et al., 1999), e requer memória espacial. Andar com redução parcial ou total da informação visual é difícil, mas é facilitado quando se conhece previamente o ambiente (Philbeck et al, 2001).

A tendência de não andar em linha reta sem informação visual é chamada veering (Boyadjian et al., 1999) e está relacionado com o mecanismo da orientação espacial. Vuillerme et al. (2002) estudaram a associação entre veering e níveis de atenção e verificaram que a distração e a atenção excessiva aumentam o veering. Crianças que participam de um programa de treinamento em ginástica artística apresentam menor veering quando comparadas com crianças que não têm experiência em ginástica olímpica (Silva e Mochizuki, encaminhado). Boyadjian et al. (1999) verificaram que os indivíduos tendem a desviar sempre para o mesmo lado quando andam; enquanto Mohr et al. (2003) não obtiveram preferências de lado no veering. Cristopher et al. (2007) questionam se o veering é resultado de pequenos distúrbios motores na marcha que se tornam mais severos quando os indivíduos caminham por percursos mais longos. Boyadjian et al. (1999) sugerem um mecanismo periférico para desempenhar o controle do veering. Logo, a orientação espacial afeta a locomoção.

A orientação espacial depende da memória (Valiquette et al., 2003) e é usada nas atividades da vida diária. Ao se locomover para um destino determinado, o cérebro, através das informações sensoriais, controla e cria a representação espacial para completar a trajetória real. Assim, o cérebro tem o papel de antecipar futuros eventos durante a locomoção, comportamento este presente em várias tarefas motoras (Pascal et al., 2002). A partir da orientação espacial, o indivíduo constrói um referencial do meio utilizando as informações sensoriais (posicionamento de seu corpo em relação ao espaço, o controle do seu tônus muscular e visão) para o êxito na execução de uma tarefa. O indivíduo deve ter domínio do corpo, interagindo-o com o meio. Quando o indivíduo passa a ter dificuldades para perceber seu próprio corpo em relação a outros objetos ou meio, dificuldades para manter-se numa determinada posição ou se locomover com segurança o risco de queda aumenta, ameaçando assim sua qualidade de vida.

Em virtude do apresentado, o problema deste estudo está resumido nas seguintes questões: Qual é a relação entre risco de quedas acidentais de idosos e orientação espacial? Será que a orientação espacial e veering se comportam de forma diferente nos idosos em comparação aos adultos? 


\section{OBJETIVOS}

\subsection{Objetivo geral}

O objetivo principal deste trabalho é estudar a relação do risco de quedas durante a locomoção sem informação visual.

\subsection{Objetivos específicos}

Os objetivos específicos deste trabalho são: a) Estudar a relação da orientação espacial e o controle postural de idosos, e b) Comparar a orientação espacial de adultos jovens e idosos.

\section{HIPÓTESES DE ESTUDO}

A partir dos objetivos específicos, buscaremos rejeitar a seguinte hipótese: $\mathrm{H}_{0}$ - $\mathrm{O}$ veering não sofrerá efeito do grupo estudado. Para encontrar resultados que possam refutar a hipótese, desenvolvemos estudos sobre o veering com adultos jovens e idosos.

\section{JUSTIFICATIVAS}

O presente estudo tem como princípio a utilização de ferramentas biomecânicas para estudar características funcionais na locomoção do idoso. O controle da locomoção exige uma integração dinâmica entre corpo e ambiente (Berthoz et al., 1999) e é dependente da memória espacial. Desta forma, a investigação do comportamento da orientação espacial é fundamental para entender a locomoção e o risco de quedas nos idosos. É conhecido o veering em crianças e adultos, mas não em idosos, o que pode ser um fator de risco de quedas. A proposta deste estudo é estudar o veering em idosos.

A atividade física proporciona benefícios biológicos para os indivíduos idosos (Kell et al., 2001; Okuma, 1998; Spirduso, 1995; Carter et al., 2002; Gregg et al., 1998); além de proporcionar bem-estar psicológico e emocional ajudando no combate às doenças psíquicas como a depressão; diminuindo o nível de estresse, ansiedade, insônia e tensão e melhorando a auto-estima e a imagem corporal (Okuma, 1997). Diversos fatores podem ameaçar a qualidade de vida do idoso e a queda é um fator restritivo à sua independência física. A relação sobre intervenção e risco de quedas (Gillespie et al., 2005; Gregg et al., 1998) sugere tipos de intervenções que podem reduzir o risco de quedas. O número de medicamentos ingeridos diariamente afeta o risco de quedas, idosos que fazem uso diário de remédios têm maior chance de sofrer queda do que aqueles que não tomam (Kelly et al., 2003; Coutinho et al., 2002; Gama et al., 2008) e, podem ser considerados como grupo de risco de quedas. Contudo, mesmo com o aumento da demanda de idosos por atividade física, os estudos que comparam a atividade física com fatores de risco de quedas por meio de variáveis biomecânica são poucos. Assim, estudamos a biomecânica da locomoção e a relação veering em idosos fisicamente ativos e idosos com risco de quedas. 


\section{REVISÃO DE LITERATURA}

A seguir apresentaremos uma revisão da literatura sobre a locomoção e quedas e sua relação com o controle postural no processo do envelhecimento para, posteriormente aprofundar o conhecimento com os estudos que abordam a principal temática deste trabalho, a orientação espacial e o veering.

\subsection{Locomoção e Quedas no envelhecimento}

O processo do envelhecimento inclui certas mudanças nos sistemas músculo-esquelético e neuromuscular que afetam o desempenho motor e que podem aumentar o risco de quedas (Huang et al., 2003).

Uma ação motora envolve um conjunto de posturas e movimentos para realizar uma tarefa e atingir uma meta (Bigongiari et al., 2009). Para a execução de uma tarefa motora é preciso o controle dos músculos, articulações e segmentos corporais para manter o controle postural. As funções do controle postural são equilíbrio, suporte do peso e estabilização (Rothwel, 1994).

Dois fatores organizam o controle postural: o equilíbrio e a orientação (Mergner et al., 1994). O controle do equilíbrio requer a ação integrada de todas as forças que estão agindo no corpo para controlar a posição do centro de massa (COM) (Mergner et al., 1994). Para manter a orientação é preciso a interpretação da informação sensorial de várias fontes para alinhar as partes do corpo com a referência da força gravitacional e de outras características do ambiente (Mergner et al., 1994).

O controle postural, portanto, usa informações sobre a posição do centro de massa (COM) com base nas informações sensoriais para relatar e reconhecer a posição e o movimento de cada parte do corpo (Mochizuki, 2002). A estabilidade postural é provida pelos ajustes posturais realizados antes do início do movimento focal (ajuste postural antecipatório, APA) e por aqueles realizados depois do início do movimento (ajuste postural compensatório, APC) (Bigongiari et al., 2009). O controle postural envolve a capacidade de se recuperar da instabilidade, de antecipá-la, e de evitá-la (Cook \& Woolacott, 2003).

Assim, uma das formas de manter a estabilidade do corpo é por meio dos mecanismos proprioceptivos (Maurer et al., 2000) e pela ação sinérgica dos músculos (Mochizuki, 2002). As correções da postura para manter o equilíbrio podem ser verificadas pelo padrão de ação muscular, pela coordenação da contração da musculatura agonista e antagonista em cada articulação (Mergner et al., 1994). O sinergismo da contração muscular numa tarefa postural depende da interação dos sistemas vestibular, visual e proprioceptivo (Mergner et al., 1994). Quando a relação de todos esses fatores não funciona em nível ótimo, como no processo do envelhecimento, o corpo fica suscetível a quedas.

As quedas são a maior causa de lesão e morte nos idosos, gerando na maioria das vezes, fraturas no quadril e no punho. No Brasil, segundo o Sistema de Informação Médica do Sistema Único de Saúde do Ministério da Saúde, entre 1979 e 1995, 54.730 pessoas morreram devido a quedas, 52\% eram idosos, dos 
quais $39,8 \%$ eram octogenários.

Um terço das pessoas com mais de 64 anos que vivem na comunidade caem uma vez por ano e $15 \%$ dos idosos com mais de 64 anos caem pelo menos duas vezes por ano (Gama et al., 2008). A maior parte das quedas têm consequiências graves (Campbell et al., 1990), resulta em fraturas $(54,5 \%)$, contusões $(13,6 \%)$ e lacerações $(12,8 \%)$ (Kelly et al, 2003). O número de idosos que caem e fraturam o quadril cresce $9 \%$ ao ano sendo que entre estes, 50\% não voltam a andar (Cummings et al., 1995; Spirduso, 1995). A maioria dos acidentes ocorre nos membros superiores $(31,2 \%)$, inferiores $(31,1 \%)$ e cabeça $(17,8 \%)$ (Kelly et al., 2003). As mulheres caem mais que os homens (Nickens, 1985), chegam a ter após os 65 anos $40 \%$ a mais de chance de sofrerem quedas quando comparadas aos homens e esta proporção aumenta a cada ano (Kelly et al., 2003). Porém, os homens quando caem sofrem lesões mais graves ou mesmo morrem (Nickens, 1985). Skelton et al. (2003) encontraram que idosos com mais de 80 anos sofrem quedas mais freqüentes, têm maior número de lesões e apresentam uma recuperação mais lenta. Sendo assim, as quedas comprometem a qualidade de vida do idoso, podendo comprometer a sua independência física.

Os principais fatores associados ao risco de quedas são: ser do sexo feminino; ter antecedente de queda; alterações na marcha; incapacidade funcional; problemas cognitivos; fazer uso de medicamentos psicotrópicos e; praticar atividade física, pois, por terem uma melhor condição física, são mais autoconfiantes e por conta disso, se arriscam mais em situações desafiadoras (Gama et al., 2008). Imediatamente após a prática de exercícios físicos o corpo do idoso é mais suscetível à queda, pois, a atividade física causa um efeito de fadiga nos músculos que envolvem o controle postural, a oscilação do COP na direção médio-lateral e a sua variabilidade aumenta em 5\% e 17\% respectivamente (Egerton et al., 2009). Em contrapartida, a prática de exercícios físicos no envelhecimento melhora a função física (Carter et al., 2002) e mostra ser efetiva na redução do risco de quedas durante as atividades da vida diária (Huang et al., 2003), pois, promove aumento da força muscular e, diminui a instabilidade do andar (Hausdorff, 2007).

A quantidade de fármacos ingerida diariamente também tem relação com risco de quedas (Kelly et al., 2003; Coutinho et al., 2002; Gama et al., 2008; Hartikainen et al., 2007). O uso de 3 ou 4 medicamentos aumenta o risco de reincidência de quedas (Hartikainen et al., 2007). O consumo diário de um fármaco incide em um aumento de $5 \%$ a mais de chance de quedas e de $100 \%$ quando se consome dez ou mais fármacos (Gama et al., 2008, Hartikainen et al., 2007). O uso de 2 ou mais ansiolíticos como os "Benzodiazepínicos" aumentam o risco de fraturas no quadril por quedas (Hartikainen et al., 2007).

Outro fator associado ao risco de quedas no envelhecimento é a instabilidade da marcha (Hausdorff, 2007). A maioria das quedas nos idosos acontece devido à perda da estabilidade enquanto caminham (Karamanidis et al., 2008 e Kesler et al., 2005), principalmente na fase do início da marcha, pois, o individuo parte de uma posição estática para uma dinâmica e cíclica, o corpo (os músculos) têm que formar uma nova estratégia para tentar restabelecer o equilíbrio e a sinergia muscular. Apesar de ser considerada uma tarefa automatizada, o andar é uma tarefa complexa para as pessoas mais velhas (Hausdorff et al., 2005), por 
associar a necessidade de desempenho do sistema cognitivo e controle postural. O sistema cognitivo abrange bons níveis de atenção e percepção durante a locomoção e, o controle postural inclui a coordenação de muitos músculos e articulações em equilíbrio dinâmico (Cook, Woollacott, 2003), ou seja, o controle dos graus de liberdade (Bernstein, 1967) durante a marcha.

O sistema locomotor interage com as informações do córtex motor, cerebelo e dos gânglios basais que recebem as informações dos sistemas visual, vestibular e proprioceptivo para produzir a ativação muscular e o movimento coordenado dos membros (Hausdorff, 2007). Quando todas essas informações estão funcionando de maneira ótima o movimento da marcha é estável. Porém, flutuações no padrão da marcha e alterações nas condições ambientais podem influenciar na dinâmica do movimento e aumentar o risco de quedas (Hausdorff, 2007). A instabilidade do andar é um fenômeno multifatorial, o controle neural e a função muscular influenciam no desempenho da marcha e podem acrescer o risco de quedas (Beauchet et al. 2008, Spring et al., 2006 e Hausdorff et al., 2005; Hausdorff, 2007).

Para andar em condições normais no meio ambiente o ser humano muitas vezes precisa se adaptar em superfícies não totalmente planas e com obstáculos mudando a velocidade, a amplitude e a freqüência do passo. A flexibilidade no modo do andar é a base fundamental da capacidade de adaptação do aparelho motor em resposta a mudanças de forças externas ou superfícies escorregadias. O comprimento e a frequiência do passo afetam a variabilidade espacial e temporal do andar (Danion et al., 2003). Andar com passadas curtas e alta freqüência requer uma maior ativação muscular dos músculos do membro inferior do que andar com passadas longas e baixa freqüência (Patla, 1985).

Em condições normais a velocidade do andar entre idosos com histórico de quedas e idosos sem antecedentes de quedas são estatisticamente parecidas (Hausdorff, 2007). Porém, os idosos com histórico de quedas apresentam maior variabilidade no tempo da passada (Hausdorff, 2007) e, quando associam a marcha a uma tarefa cognitiva, diminuem a velocidade da marcha.

Beauchet et al. (2008) classificaram 213 idosos (84,4 45,5 anos) em três grupos (sem histórico de quedas, uma queda, duas ou mais quedas ao longo de 12 meses) e associaram a locomoção ao longo de $10 \mathrm{~m}$ com uma tarefa cognitiva (contar do número 50 ao 1). Idosos reincidentes em queda andam em velocidade menor e diminuem mais a velocidade da marcha quando associada à tarefa cognitiva. Adultos e idosos sem antecedentes de queda conseguem manter a marcha em um padrão estável quando realizam simultaneamente uma tarefa cognitiva enquanto que, idosos com antecedentes de queda apresentam maior variabilidade na fase de balanço da marcha e dificuldade para estabilização do tronco (Spring et al., 2006).

Bonnard et al. (2000) investigaram os mecanismos fisiológicos envolvidos na flexibilidade da relação frequiência e amplitude do passo na locomoção humana. Os sujeitos andavam com velocidade constante com combinações de preferência e não preferência de freqüência e amplitude de passo. Ao andar com frequiência e amplitude de passo preferida o aumento da velocidade não muda o padrão do ângulo articular e da ativação dos músculos do membro inferior. Ao andar com passada curta e alta freqüência, há o aumento da ativação 
muscular, e da coativação dos músculos quadríceps e ísquiotibiais na fase de balanço. Portanto, ao mudar o padrão do andar, o aparelho motor se adapta gastando mais energia para manter a sinergia do movimento (Bonnard et al., 2000). Porém, como a mudança no parâmetro do passo aumenta a variabilidade espacial e, quase sempre, aumenta a variabilidade temporal (Danion et al., 2003), é muito difícil criar um padrão de alteração da marcha pois, tais alterações vão depender das combinações dos parâmetros tamanho e frequiência do passo, o que torna difícil a comparação entre estudos que manipulam essas variáveis.

Durante a marcha o sistema locomotor move o corpo, passo a passo, de maneira aparentemente constante. Porém, flutuações e interações ocorrem a nível microscópico, como um ritmo fractal (Hausdorff et al., 2001), existe portanto, uma grande relação entre a locomoção humana e a análise aleatória e esta, muda conforme a idade. Quando os adultos caminham ao longo de uma hora em diferentes velocidades $(1 \mathrm{~m} / \mathrm{s}, 1,3$ $\mathrm{m} / \mathrm{s}, 1,7 \mathrm{~m} / \mathrm{s}$ ) o coeficiente de variação da análise espectral indica que as variações do ritmo da marcha não são aleatórias e que as séries temporais tem correlações de longo alcance (Hausdorff et al., 2001), o caminhar em velocidades menores não altera o ritmo fractal da marcha. Já quando os idosos caminham nas mesmas condições, a detrend flutuation analysis indica que o intervalo de flutuação do passo é mais aleatório e menos correlacionado (Hausdorff et al., 2001). A magnitude da correlação entre o intervalo do passo é independente da velocidade da marcha e da variabilidade do passo (Hausdorff et al., 2001). As alterações na dinâmica fractal do passo com o avançar da idade, portanto, pode ser uma evidência que as mudanças no ritmo fractal da marcha do idoso não é simplesmente resultado da diminuição da velocidade da marcha ou do aumento da variabilidade do passo com o envelhecimento (Hausdorff et al., 2001). Aparentemente a correlação entre o intervalo do passo depende de alguns aspectos do sistema de controle neuro- muscular e não está diretamente relacionado com a velocidade da marcha (Hausdorff et al., 2001).

O tronco é o segmento do corpo que possui a maior massa corporal (Winter, 1990) o que poderia influenciar na dinâmica da estabilidade do corpo, principalmente na locomoção. Na marcha os membros superiores são menos suscetíveis a pequenas perturbações iniciais do que os membros inferiores (Gu Kang et al., 2009). Os idosos apresentam uma menor estabilidade dinâmica em todos os segmentos corporais do que os adultos, em especial na oscilação do tronco durante a marcha (Gu Kang et al., 2009). A diminuição da condução ou da velocidade dos impulsos nervosos e da capacidade ou velocidade de interpretação das informações recebidas dos sistemas sensoriais e, o aumento do tempo das respostas reflexas no envelhecimento (Hausdorff, 2007) pode influenciar na capacidade e velocidade de correção do tronco e no aumento de sua oscilação (Gu Kang et al., 2009) em situações de maior instabilidade.

Bruijn et al. (2009) estudaram o efeito da velocidade da marcha na estabilidade dinâmica do tronco por parâmetros não- lineares em adultos, através do expoente de Lyapunov que quantifica a estabilidade estimando a porcentagem de divergência das variáveis cinemáticas em séries temporais.Os sujeitos caminhavam em uma esteira em velocidades de 0,62 a 1,72 m/s. Nos 50 primeiros passos (componente curto do expoente) oscilação do tronco na direção ântero- posterior diminuiu com o incremento da velocidade; na direção médio- lateral 
aumentou nas velocidades até $1,28 \mathrm{~m} / \mathrm{s}$ e depois diminuiu; na direção vertical aumentou com o incremento da velocidade. No intervalo de 400 a 1000 passos (componente longo do expoente) oscilação do tronco nas direções ântero-posterior e vertical aumentou com o incremento da velocidade; na direção médio-lateral diminuiu com o aumento da velocidade. A correlação positiva em todas as direções entre o componente curto do expoente e o desvio padrão da média do ciclo do passo e, a correlação negativa na direção ântero-posterior entre o componente longo do expoente e o desvio padrão da média do ciclo do passo sugere que andar em velocidades mais baixas não necessariamente é mais estável do que andar em velocidades mais rápidas (Bruijn et al., 2009).

Durante a locomoção as informações sensoriais são essenciais para o julgamento perfeito da distância da meta, da direção e velocidade do movimento, da orientação interna entre os segmentos do corpo com a gravidade e o meio ambiente (Deshpande et al., 2007). O sistema nervoso central integra informações dos sistemas visual, vestibular e somotossensorial para gerar o movimento apropriado para a execução da tarefa desejada (Deshpande et al., 2007). O equilíbrio postural durante a locomoção é influenciado por dois mecanismos: o mecanismo intrínseco do controle postural e o mecanismo extrínseco do ambiente e das atividades que o desafiam (Harwood, 2001). A visão é um dos quatro mecanismos sensórios que detectam perturbações no equilíbrio, atua junto com o sistema vestibular, a propriocepção da cabeça e dos membros inferiores e as informações táteis dos pés (Harwood, 2001).

Os receptores cutâneos dão informação da posição do corpo e das extremidades no meio ambiente em relação à cabeça (Harwood, 2001). Quando a informação sensorial é limitada (por neuropatia periférica ou por superfícies instáveis) o sistema vestibular aumenta sua atividade (Horak et al., 2001). O sistema vestibular contribui na percepção espacial dando informação sobre a posição da cabeça e do movimento de rotação e translação da cabeça (Pascal et al.,2002), mas, é o sistema visual que predomina na referência espacial (Mergner et al., 1994).

O’Connor et al. (2009) estudaram o efeito da perturbação visual na oscilação do tronco durante a locomoção de adultos. A oscilação na direção médio-lateral é mais afetada pela visão do que a oscilação na direção ântero-posterior (O’Connor et al., 2009), o que sugere que, a visão é responsável pelo controle da oscilação do tronco na direção médio- lateral durante a locomoção.

Os idosos são mais dependentes da visão para a manutenção do controle postural do que os adultos (Harwood, 2001), em situações de restrição da informação visual há um grande decréscimo na estabilidade postural (Kesler et al., 2005). Ambientes com pouca luz (Huang et al., 2003) e problemas na visão (Harwood, 2001) aumentam o risco de quedas nos idosos.

O declínio da estabilidade (Choy et al., 2003) com os olhos fechados inicia-se aos 40 anos, as mulheres entre os 60 e 70 anos são mais instáveis que as mulheres jovens com olhos fechados. A oscilação postural aumenta em 50\% ou mais em tarefas com os olhos fechados e, está associada ao risco de quedas (Harwood, 2001). O tempo de reação para manter o equilíbrio do corpo frente a uma perturbação externa é maior nos 
idosos (Harwood, 2001), o que causa mudanças no uso das sinergias neuromusculares e quanto ao medo de cair (Cosme et al., 2004). A menor estabilidade influencia o padrão da marcha.

$\mathrm{Na}$ ausência de luz os idosos tendem a caminhar mais devagar (14,3\% mais devagar comparado com o andar de olhos abertos) mantendo o padrão da marcha (provavelmente andam mais devagar por aumentar o nível de atenção), porém, idosos com doenças que afetam a locomoção além de diminuir a velocidade da marcha (15,8\% mais devagar comparado com o andar de olhos abertos), reduzem o tempo da fase de balanço e aumentam a variabilidade do passo (Kesler et al., 2005). A variabilidade do tempo do passo na marcha está associada com o medo de cair (Kesler et al., 2005). O aumento da instabilidade e dependência da visão é proporcional ao aumento do risco de quedas (Harwood, 2001).

O processamento visual depende da localização do campo visual quando a informação é reconhecida ou recuperada, da percepção do espaço/ ambiente, da necessidade de reconhecer ou recuperar a profundidade relativa da informação (Mergner et al., 1994). Para andar em ambientes escuros o movimento é monitorado com base em sinais internos como mudanças na posição dos membros e músculos ou por acelerações detectadas pelo sistema vestibular (Philbeck et al., 2001).

Para a manutenção do controle postural e da locomoção existem duas categorias de processamento visual, o chamado fluxo ótico e, o chamado reconhecimento da velocidade global, que fornecem a informação da velocidade e da trajetória através do campo visual (Philbeck et al., 2001; Deshpande, et al., 2007; Mergner et al., 1994) e, a informação da magnitude e da direção do movimento observado (Mergner et al., 1994). O fluxo ótico é uma importante fonte de informação para a auto- percepção do movimento no espaço/ ambiente (Bertin et al., 2004). Os humanos conseguem perceber a direção do movimento da cabeça através do fluxo ótico com bastante acurácia e quase que instantaneamente.

A visão normal pode ser perturbada pela informação do sistema vestibular o que sugere que a performance na direção da locomoção (percepção da orientação espacial) sofre influência da regulação vestibular (Deshpande et al., 2007). Um estímulo de pequena duração no sistema vestibular pode influenciar na percepção da trajetória por um tempo maior que um estímulo visual (Bertin et al., 2004). Estímulos vestibulares causam efeito positivo na visão: um estímulo vestibular linear causa impressões de translações na visão e um estímulo vestibular de rotação causa impressões de rotações na visão (Bertin et al., 2004). O sistema vestibular sofre declínio com o envelhecimento, quando os idosos andam com olhos abertos sobre efeito de uma perturbação vestibular desviam mais da trajetória e oscilam mais o tronco na tentativa de restabelecer o equilíbrio do corpo em comparação aos adultos (Deshpande et al., 2007).

A informação visual também é um importante fator que influencia no equilíbrio durante a locomoção em superfícies sinuosas ou com obstáculos. A informação visual com relação à posição e tamanho de um obstáculo é usada para planejar e controlar adaptações necessárias durante a marcha (Rietdyk et al., 2006). Ao andar em superfícies irregulares os idosos aumentam a variabilidade do passo (Marigold et al., 2008), tendem a caminhar mais devagar (Lowrey et al., 2007) e com passos mais curtos (Marigold et al., 2008), diminuir a 
velocidade da aterrissagem do pé ao ultrapassar o obstáculo (Lowrey et al., 2007), e apresentar uma maior aceleração do tronco na direção médio- lateral o que pode aumentar a chance de quedas (Marigold et al., 2008).

Devido à diminuição da funcionalidade dos sistemas sensoriais no envelhecimento, o andar em diferentes superfícies como em terrenos irregulares, acidentados, escorregadios ou pedregosos fica mais complicado, pois, os idosos têm dificuldade de restabelecer o equilíbrio frente a um deslize ou a um tropeção ou escorregão (Lowrey et al., 2007; Marigold et al., 2008). Porém, o uso da visão junto com a experiência prévia do terreno/ lugar pode ser usado para o controle do equilíbrio durante a locomoção em terrenos instáveis (Deshpande et al., 2007).

Contudo, há muitas controvérsias sobre o papel da visão e qual a informação específica que é usada para guiar a trajetória durante a locomoção (Patla et al., 2004). Indivíduos cegos conseguem se locomover no espaço e com o treinamento de navegação melhoram sua orientação espacial (Castro et al., 2004). Porém, a seleção de qual trajetória a seguir a fim de ultrapassar obstáculos durante a locomoção é dependente da visão, do ambiente e do movimento da cabeça, ou seja, ao caminhar em ambientes sinuosos há maior frequiência de movimentação da cabeça (rotações) para poder visualizar o ambiente (Patla et al., 2004). A decisão da rota da trajetória a seguir com obstáculos não é traçada com base nos detalhes explícitos do ambiente, porém, quando há a informação detalhada do obstáculo a ultrapassar o tempo de reação para iniciar o movimento é menor (alteração da trajetória) (Patla et al., 2004). Na verdade a trajetória é planejada com base na visão global das características gerais do ambiente e dos obstáculos e do objetivo/ fim da rota para alcançar o caminho mais seguro (Patla et al., 2004). Ter a informação visual da posição do objeto a ser ultrapassado durante a locomoção é mais importante do que ter a informação visual dos membros inferiores para controlar o momento exato de ultrapassar o objeto (Rietdyk et al., 2006).

Pelo exposto, a visão influencia na locomoção que é afetada por fatores intrínsecos e extrínsecos. A boa sinergia muscular e a capacidade de resposta e adaptação às mudanças no meio ambiente são alguns fatores responsáveis pela manutenção dos movimentos da vida diária e da diminuição do risco de quedas durante a locomoção em idosos. Porém, todo deslocamento pelo meio, só é possível com êxito se o indivíduo tiver um bom controle da orientação espacial, e, é esse tópico que vamos abordar no próximo item.

\subsection{Orientação espacial e veering}

Orientação é a capacidade de dirigir uma atividade em função da disposição do mundo exterior (Perrin \& Lestienne, 1998), dependente do bom funcionamento integrado de três sistemas: sensorial, capaz de detectar a direção e as variações locais de um campo; efetor, capaz de dirigir a atividade ou o desenvolvimento do organismo numa dada direção; controle, que regula a atividade do sistema efetor em função das mensagens recebidas pelo sistema sensorial (Perrin \& Lestienne, 1998).

A orientação espacial cinestésica é a percepção para a localização e a orientação do corpo no espaço 
independente da visão (Haywood \& Getchell, 2001). O controle da orientação espacial durante tarefas de navegação e locomoção requer uma atualização dinâmica da representação da relação entre o corpo e o meio ambiente e isso depende da integração central de múltiplas informações sensoriais e da comparação dos sinais sensoriais recebidos ou percebidos com o plano da trajetória, com o esquema corporal e com a memória do passado (Vuillerme et al., 2002). A partir da habilidade de coordenar a ação com a direção e distâncias relativas que as noções conceituais de origem, estado e destino se constroem em tarefas de orientação espacial (Castro et al., 2004).

Segundo Kausler (1994), a memória depende da qualidade e da quantidade de vezes que determinado evento é requisitado, a partir dos 50 anos a memória de curto prazo decresce cerca de $10 \%$ e a memória temporal (relacionada à seqüência de eventos) decresce $25 \%$. A organização espacial depende da memória, quando o ser humano se locomove em um ambiente desconhecido ele faz uso de referenciais intrínsecos e da perspectiva da visão para interpretar a estrutura espacial do novo meio (Valiquette et al., 2003). A memória espacial sofre declínio partir dos 60 anos (Kausler, 1994).

Quando o indivíduo recebe a informação visual da trajetória, ao andar no escuro, consegue realizar a trajetória com base na reconstrução interna gerada pela informação visual memorizada anteriormente, porém, após muitas repetições sem a visão ele começa a perder a orientação por causa da perda da referência espacial (Philbeck et al., 2001).

A cabeça é essencial para o controle do movimento e interpretação das informações sensoriais durante a locomoção. Quando o indivíduo se locomove ou tem que atravessar um obstáculo o movimento da cabeça para realinhar a trajetória antecede o movimento do tronco o que representa o realinhamento/ ajuste do centro de massa (Patla et al., 2004). A cabeça desvia na direção da futura trajetória cerca de 500ms antes da mudança em $90^{\circ}$ do corpo durante a locomoção em uma trajetória circular ou curvilínea com olhos abertos ou fechados e, em velocidades mais baixas a cabeça começa o desvio mais cedo (Pascal et al., 2002).

Se o fluxo ótico guia a locomoção então, a dinâmica da movimentação de antecipação da cabeça seria afetada durante a locomoção de olhos fechados, ou seja, sem visão a cabeça não deslocaria antes do tronco. Porém, mesmo sem visão, o movimento da cabeça continua desviando na direção da trajetória antes do tronco, o que sugere que, a memória espacial fornece as informações para manter a mesma estratégia de controle do movimento e que, a visão pode não ser essencial para direcionar a locomoção (Pascal et al., 2002).

Thomson (1983) estudou o controle visual durante a locomoção, a fim de saber se a manipulação da visão gera efeito na acurácia e se existem modelos para o controle motor visual. Os seis experimentos diferentes realizados manipulavam a informação visual para atingir um alvo com precisão em diferentes distâncias (de 3 a 21m), sendo que nos dois últimos experimentos além da visão, os indivíduos confrontavam a tarefa de locomoção com a de arremesso de um objeto no alvo. A locomoção pode ser guiada com precisão sobre o alcance substancial da distância, quando a visão é completamente excluída 5 segundos depois da visualização do alvo, com acurácia em até $9 \mathrm{~m}$, a partir de $12 \mathrm{~m}$ o erro variável aumenta consideravelmente, ou 
seja, o desvio do alvo. O tempo é a variável fundamental para determinar a acurácia na locomoção sem visão, quanto maior for o tempo sem visão antes de iniciar a tarefa menor será a precisão, mas, se a tarefa for realizada com o tempo total de até 8seg sem visão é possível manter a precisão. É possível reter as informações sobre o ambiente de forma generalizada por até 8seg sendo flexível, ou seja, o indivíduo consegue reorganizar seu comportamento para mudar a tarefa sem ter que consultar a visão direta. É possível reter as informações além do tempo limite ( $8 \mathrm{seg}$ ), porém, o planejamento da tarefa se torna inflexível.

Enfim, em distâncias de até 5m a informação sobre a localização do alvo é internalizada de forma relativamente estável e não é afetada pela passagem do tempo, dentro desse alcance a acurácia é boa e o atraso do tempo (tempo entre ver o alvo e ficar sem visão antes do início da tarefa) no decorrer do tempo sem visão é excluída como o pequeno efeito da acurácia, a programação motora tem estratégias limitadas, sendo inflexíveis (Thomson, 1983). Em distâncias de até $21 \mathrm{~m}$ o tempo parece ser fator primordial, a acurácia é maior quanto menor for o tempo entre excluir a visão e alcançar o alvo e, esse tempo usa a memória de curto prazo e tem um limiar de 8 segundos, a informação é internalizada de forma mais genérica permitindo que a atividade seja controlada em distâncias maiores, sendo flexíveis para permitir que a atividade motora seja reorganizada sem a necessidade de consultar a visão (Thomson, 1983).

Ter somente a memória da estrutura do espaço, portanto, não é suficiente para a reconstrução da trajetória (Thomson, 1983), porém, guardar informações externas (ex saliências/ depressões no solo ou a posição do sol) no início ou ao longo da trajetória antes de iniciar o movimento ajuda a orientação e melhora a performance na locomoção sem visão (Philbeck et al., 2001). A informação da visão durante a locomoção é importante na reação e adaptação do movimento em mudanças no ambiente e não depende/ solicita a memória quando o deslocamento é de olhos abertos, seu poder de mudança da trajetória é limitado pela inércia do movimento (Patla et al., 2004). A decisão da rota da trajetória a seguir com obstáculos não é traçada com base nos detalhes explícitos do ambiente, porém, quando há a informação detalhada do obstáculo a ultrapassar o tempo de reação para iniciar o movimento é menor (alteração da trajetória) (Patla et al., 2004). Na verdade a trajetória é planejada com base na visão global das características gerais do ambiente e dos obstáculos e do objetivo/ fim da rota para alcançar o caminho mais seguro (Patla et al., 2004). Porém, quando a locomoção é feita na ausência da visão a acurácia da tarefa parece depender: da disponibilidade da informação acurada sobre a distância e a direção do alvo; da habilidade de internalizar informações sobre o caminho; da habilidade de planejar e monitorar a execução da ação motora desejada, ou seja, do passo; da habilidade de manter atualizada a posição com a representação internalizada da base (Thomson, 1983).

A tendência de não manter o deslocamento pelo ambiente em linha reta quando o ser humano caminha sem visão, ou seja, a tendência do indivíduo de sofrer desvios na locomoção de olhos fechados é chamada de veering (Vuillerme et al., 2002; Boyadjian et al.,1999). A habilidade de andar em linha reta depende da disponibilidade e da qualidade da informação sensorial sobre a direção da trajetória, da capacidade de executar movimentos na direção pretendida (Kallie et al., 2007), da capacidade de internalizar informação da trajetória 
de forma mais genérica e das partes do corpo (Thomson, 1983). A visão é usada para o deslocamento preciso em linha reta no meio ambiente (Vuillerme et al., 2002). Quando indivíduos tendem a desviar sempre para o mesmo lado são chamados de homotrópicos e, quando não há um padrão de desvio são chamados de indivíduos heterotrópios (Boyadjian et al., 1999). Esse comportamento parece estar ligado à manifestação adicional da preferência lateral (lateralidade) no comportamento motor lateralidade ou à assimetria dos membros (Boyadjian et al., 1999; Day et al., 1997).

Indivíduos que têm a perna direita como dominante tendem a desviar para o lado esquerdo e, indivíduos que têm a perna esquerda como dominante a tendem a desviar para o lado direito (Day et al., 1997). A informação auditiva gerada por barulhos externos faz com que o indivíduo desvie para o lado do som e, a adição de objetos (como carregar uma bolsa em uma das mãos) faz com que o deslocamento seja para o lado oposto do lado do membro que carrega o objeto (Millar, 1999).

A maioria das pessoas tende a ser homotrópica (Boyadjian et al., 1999; Day et al., 1997). Boyadjian et al.(1999) estudaram a origem do veering em indivíduos adultos homotrópicos, calculando os erros constante, variável e absoluto. Os sujeitos percorriam sem visão uma trajetória até o centro de um círculo de raio de $15 \mathrm{~m}$. $\mathrm{O}$ veering foi mensurado pela distância perpendicular do ponto de chegada até a linha pretendida e desviaram nas seguintes condições: 2,5m andando, 3,2m andando em cadeira de roda e, $4 \mathrm{~m}$ sendo levado em cadeira de roda guiando verbalmente a trajetória. Os sujeitos foram homotrópico nas duas primeiras condições e heterotrópico na terceira condição o que sugeriu que o veering é um mecanismo periférico, relacionado com o desequilíbrio entre lados do corpo, pois se fosse central o indivíduo homotrópico desviaria sempre para o mesmo lado em qualquer condição de tarefa (Boyadjian et al., 1999).

O sistema proprioceptivo de ginastas é mais apurado, pois, nas mesmas condições de Boyadjian et al. (1999), o desvio da trajetória foi menor nas duas primeiras condições (Danion et al., 2000). Os indivíduos cegos também apresentam veering, em distâncias maiores que $30 \mathrm{~m}$ podem desviar em média $7 \mathrm{~m}$ da trajetória pretendida (Guth \& LaDuke, 1994). Esses resultados sugerem que o veering pode ser afetado pelo nível de treinamento de tarefas complexas que exigem controle sensório - motor apurado e que, os sistemas proprioceptivo e vestibular não são capazes de suprir totalmente a falta da visão.

O veering também pode ser afetado pelo nível de atenção. Vuillerme et al (2002) estudaram o veering em adultos andando sem visão ao longo de uma trajetória de $15 \mathrm{~m}$ nas condições: andar pensando mentalmente em nomes sendo advertidos para ter atenção no andar, andar sendo instruídos a manter a atenção na tarefa, andar sem instrução alguma (condição controle). A segunda condição foi a que apresentou o maior desvio da trajetória. $\mathrm{O}$ excesso ou a pouca atenção prejudica a desempenho em tarefas de orientação espacial e aumenta o veering (Vuillerme et al., 2002).

Quando a referência visual não está disponível o sistema vestibular e os músculos do pescoço aumentam sua contribuição no controle postural para planejar e manter a orientação na locomoção (Deshpande et al., 2005). Para compensar a diminuição da acurácia do sistema vestibular com o avançar da 
idade o corpo humano aumenta a propriocepção dos músculos do pescoço (Deshpande et al., 2005). Estímulos vibratórios nos músculos dorsais do pescoço durante a locomoção em linha reta fazem o ser humano desviar para o lado oposto do estímulo (Deshpande et al., 2005). A informação da aceleração da cabeça captada pelo sistema vestibular é usada para manter a estabilidade na direção médio- lateral durante a locomoção (Deshpande et al., 2005). A velocidade de deslocamento do COM no sentido médio-lateral é um importante predecessor da magnitude do desvio da trajetória (Deshpande et al., 2005). A variabilidade do COM no desvio da trajetória de 6,5m de olhos fechados até um alvo específico, mensurada pela representação do COM por cinemetria, no sentido médio lateral é de 76\% nos adultos e $87 \%$ nos idosos (Deshpande et al., 2005).

Para tentar entender o causa do veering Kallie et al.(2007) realizou três experimentos. No primeiro estudou o comportamento do veering na locomoção ao longo de $9,14 \mathrm{~m}$ entre adultos cegos e adultos com visão, mas, vendados. Não houve diferenças entre os grupos, a média do erro absoluto variou de 0,45 a $1,74 \mathrm{~m}$. A experiência visual, portanto, não é fator que influencia a locomoção em linha reta na ausência de visão.

Se o ser humano for capaz de regular sua trajetória sem visão usando o feedback dos sistemas vestibular, proprioceptivo e informações sinestésicas então, os canais semicirculares do sistema vestibular irão detectar a aceleração da trajetória e poderão detectar um desvio em curva da trajetória. As informações sinestésicas dos músculos e das articulações dos membros inferiores poderão proporcionar avisos sobre o desvio da trajetória e movimentos compensatórios poderão corrigir o erro. Assim, talvez o ser humano possa detectar melhor desvios na trajetória quando andam em curva. No segundo experimento, Kallie et al.(2007) verificaram se o veering estava relacionado com a sensibilidade de detectar desvio da trajetória em curva em adultos cegos e vendados. Os resultados não mostraram relação direta entre a sensibilidade de detectar trajetórias em curvas e a habilidade em andar em linha reta. O veering não é limitado pela capacidade de detectar trajetória em curva. Talvez a explicação para o comportamento do veering seja que o sistema motor não é capaz de detectar as perturbações sinestésicas nos músculos e articulações durante o desvio da trajetória.

No terceiro experimento, Kallie et al.(2007) verificaram se o veering pode ser reduzido com indicadores estáticos ou dinâmicos da direção pretendida. Nas duas condições houve veering, os resultados mostraram que o alinhamento da postura é mais efetivo para dar a direção no andar do que indicadores externos. Esse resultado sugere que a melhor estratégia para diminuir o veering em cegos seria adicionar um referencial perpendicular a trajetória pretendida para que o indivíduo alinhe costas e inicie a trajetória.

O controle do veering é essencial para o êxito em tarefas de locomoção com pouca ou nenhuma luz. A percepção do movimento depende da integração de modelos internos com informações detectadas pelos sistemas sensoriais, porém é difícil determinar como a memória e os sinais recebidos são combinados e transformados em um único fim para planejar a trajetória durante a locomoção sem visão. Nenhuns dos estudos apresentados estudaram o comportamento do veering em idosos. Será que idosos que participam de um programa de atividade física com exercícios de equilíbrio e controle motor apurado podem apresentar menor veering como as ginastas? Será que o veering é afetado pelo envelhecimento? Como será o 
comportamento da orientação espacial em idosos que têm risco de quedas? Na tentativa de responder essas questões que surgiu o problema desse estudo.

\section{MATERIAL E MÉTODO}

\subsection{Sobre os procedimentos éticos para desenvolvimento do projeto de pesquisa}

Este estudo foi submetido e aprovado pela Comissão de Ética em Pesquisa da EEFEUSP. O projeto segue os procedimentos e condutas indicados pelos aspectos éticos e legais estabelecidos pelo Conselho Nacional de Saúde do Ministério da Saúde, especialmente em relação à Resolução no 196, de 10/10/1996, do Conselho Nacional de Saúde.

\subsection{Público alvo}

O público-alvo deste estudo é a população adulta, com idade entre 18 e 80 anos de idade. A partir deste público-alvo selecionamos três grupos, com faixas etárias distintas, classificados como: adultos, idosos praticantes de atividade física (idoso AF), idosos com risco de quedas (idoso RQ). Os grupos amostrais deste estudo foram montados, respeitando os seguintes critérios de inclusão e exclusão:

Os critérios de inclusão do grupo adulto são: ter idade entre 18 e 35 anos; ser fisicamente ativo de acordo com a classificação do IPAQ (International Physical Activity Questionnaire) (Pardini et al, 2001) (ANEXO 3 e ANEXO 4), não ter sofrido lesão ou trauma neuromuscular ou ósteo-articular no aparelho locomotor nos 6 meses antes da coleta dados; não ter problemas cardiopulmonares que impeçam o desenvolvimento de atividades físicas aeróbicas; não ser portador de doença crônico-degenerativa que afete a locomoção. Os critérios de inclusão do grupo idoso praticante de atividade física são: ter idade no período de coleta de dados entre 65 e 80 anos (segundo as orientações da OMS para países em desenvolvimento); ser fisicamente ativo de acordo com a classificação do IPAQ (Pardini et al, 2001) (ANEXO 3 e ANEXO 4), capaz de realizar todas as atividades autônomas da vida diária (Matsudo, 2000; Spirduso, 1995; Rikli \& Jones, 1999) (ANEXO 2), exercícios de intensidade moderada, esportes de resistência e jogos (Cotton, 1998); fazer parte de um programa de atividade física que estimula o treino das capacidades físicas investigadas (equilíbrio, organização postural e orientação espacial) por no mínimo dois anos; não ter sofrido lesão ou trauma neuromuscular ou ósteo-articular no aparelho locomotor nos 6 meses antes da coleta; não ter problemas cardiopulmonares que impeçam o desenvolvimento de atividades físicas aeróbicas; não ser portador de doença crônico-degenerativa que afete a locomoção. Os critérios de inclusão do grupo idoso com risco de queda são: ter idade no período de coleta de dados entre 65 e 80 anos (segundo as orientações da OMS para países em desenvolvimento); capaz de realizar todas as atividades autônomas da vida diária (Matsudo, 2000; Spirduso, 1995; Rikli \& Jones, 1999) (ANEXO 2); ter labirintite ou fazer uso simultaneamente de mais de três medicamentos diários (Gama et al, 2008; Hartikainen et al, 2007); não ter sofrido lesão ou trauma 
neuromuscular ou ósteo-articular no aparelho locomotor nos 6 meses antes da coleta; não ter problemas cardiopulmonares que impeçam o desenvolvimento de atividades físicas aeróbicas; não ser portador de doença crônico-degenerativa que afete a locomoção. Os critérios de exclusão do grupo adulto e do grupo idoso praticante de atividade física são: ser portador de doença congênita ou incapacidade física que impeça a locomoção independente e sem auxílios; não ser capaz de caminhar de forma independente e segura com os olhos fechados, apresentar problemas clínicos que alterem o funcionamento adequado do sistema visual e vestibular. Os critérios de exclusão do grupo idoso risco de queda são: ser portador de doença congênita ou incapacidade física que impeça a locomoção independente e sem auxílios; não ser capaz de caminhar de forma independente e segura com os olhos fechados, apresentar problemas clínicos que alterem o funcionamento adequado do sistema visual.

\subsection{Amostra}

Participaram deste estudo 27 indivíduos adultos com 25,22 $\pm 4,59$ anos, 1,68 $\pm 0,10 \mathrm{~m}$ de estatura,

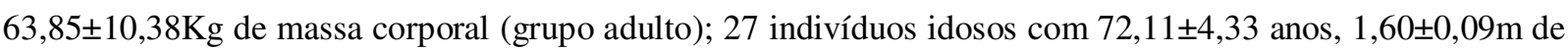
estatura, 68,55 $\pm 13,07 \mathrm{Kg}$ de massa corporal (grupo idoso atividade física - idoso AF); 12 indivíduos idosos com 72,33 $\pm 6,05$ anos, $1,57 \pm 0,08 \mathrm{~m}$ de estatura, $67,41 \pm 10,94 \mathrm{Kg}$ de massa corporal (grupo idoso risco de queda - idoso RQ).

Todos os sujeitos eram saudáveis e respeitaram os critérios de inclusão e exclusão indicados anteriormente. Antes da coleta os voluntários foram informados acerca dos procedimentos a serem adotados, após o qual assinarão o Termo de Consentimento que foi aprovado pela Comissão de Ética em Pesquisa da EEFEUSP (ANEXO 5).

\subsection{Protocolo experimental}

Os sujeitos responderam questionários sobre histórico de quedas, doenças, ingestão diária de medicamentos (ANEXO 1), a capacidade funcional (Matsudo, 2000; Spirduso, 1995; Rikli \& Jones, 1999) (ANEXO 2) e nível de atividade física (Pardini et al., 2001) (ANEXO 3) e ANEXO 4) . A partir dos critérios de inclusão e exclusão definimos os grupos: grupo adulto, grupo idoso praticante de atividade física (idoso $\mathrm{AF}$ ) e idoso com risco de quedas (idoso RQ).

Foi realizada uma avaliação antropométrica (estatura e massa corporal), e os seguintes testes: teste de mobilidade Berg (ANEXO 6), teste de mobilidade Tinetti (ANEXO 7), teste de marcha Tinetti (ANEXO 8) (Demura et al., 2007; Silva et al., 2008). Os testes de mobilidade e de marcha foram realizados para relacionar com os dados obtidos e avaliar o risco de quedas.

A tarefa inicial se define em posicionar o sujeito em pé no centro de um dos lados de quadrado $15 \times 15 \mathrm{~m}$, com os pés alinhados e com os calcanhares encostados em um artefato de madeira de $30 \mathrm{~cm}$ de altura (step), de frente para um alvo distante $15 \mathrm{~m}$ em linha reta (início - Figura 1). Um acelerômetro que mede as acelerações 
em três direções perpendiculares (EMG System) com um cabo de $30 \mathrm{~m}$ foi fixado nas costas do sujeito entre as vértebras L1 e L2. O sujeito foi instruído a caminhar em linha reta com os olhos abertos em direção ao alvo distante $15 \mathrm{~m}$ da sua posição inicial para reconhecimento do local e da tarefa. A seguir foi colocada uma venda em seus olhos e um protetor de ouvido para diminuir sons externos. O sujeito foi instruído a caminhar da mesma forma que caminhou de olhos abertos, na mesma velocidade e em direção ao alvo em linha reta, após o comando sonoro do examinador: "pode ir". O sujeito foi alertado que um examinador estaria do se lado para sua segurança e que pediu para que ele parasse quando chegasse do outro lado do local da tarefa a fim de eliminar o medo de caminhar de olhos vendados.

Quando o sujeito chegava à posição fim (Figura 1) o examinador pediu para que ele parasse e caminhou com ele de volta a posição início (Figura 1). A tarefa foi realizada 10 vezes de olhos fechados em um único bloco e, em nenhum momento foi retirada a venda dos olhos e o fone de ouvido. Somente o caminho de ida (sentido da trajetória da Figura 1) foi usado para a análise dos dados.

O ambiente onde foi realizada a coleta de dados estava silencioso com piso emborrachado antiderrapante, típico para prática de esportes de quadra, para evitar que os sujeitos escorregassem ao caminharem.

A linha preenchida representa o percurso pretendido e a linha tracejada o realizado (Figura 1). Pela diferença entre a linha preenchida e a tracejada, obtêm-se o veering.

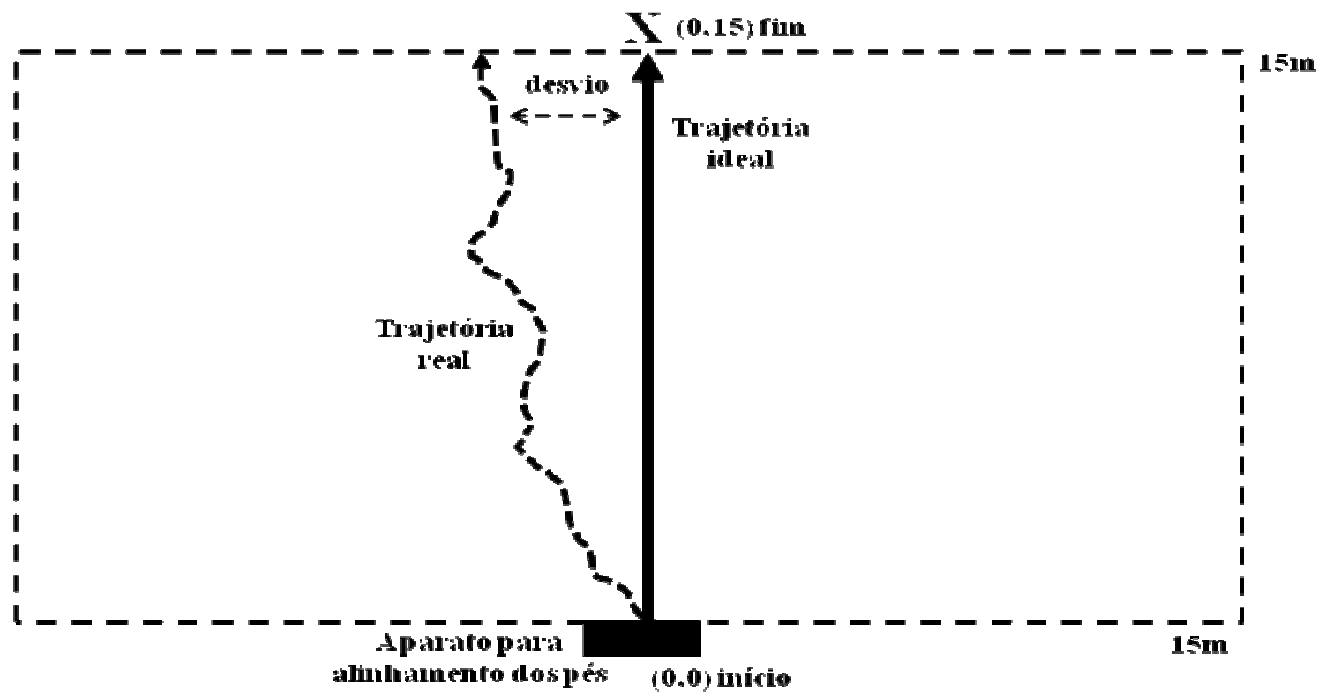

FIGURA 1 - Tarefa proposta: posiciona-se o indivíduo no início com os calcanhares alinhados em $90^{\circ}$ com o aparato de madeira $(0,0)$, ao comando sonoro caminha em direção ao X, posição final $(0,15)$. A partir da diferença entre a trajetória pretendida (trajetória ideal) e a realizada (trajetória real) mensura- se o

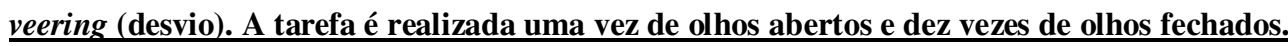


O diagrama de blocos (Figura 2) ilustra o procedimento experimental adotado neste estudo.

Após a execução da tarefa os dados obtidos foram filtrados e passaram por uma dupla integração numérica para que possa ser gerada a coordenada posição. A série temporal do deslocamento foi determinada por meio de análise do DFA (Detrended Flutuation Analysis) e de Random Walk Analysis e, o desvio da direção do alvo, o erro absoluto, o erro relativo, o erro variável e o ângulo do desvio foram determinados por estatística inferencial. Os dados foram analisados inter- sujeito (análise entre os grupos) e entre os fatores de risco de quedas (dados dos testes de mobilidade e marcha).

A partir da interpretação dos dados podemos fazer as relações que foram propostas neste estudo: estudar a relação da orientação espacial com o controle postural de idosos; comparar a orientação espacial de adultos e de idosos; relacionar a orientação espacial com o risco de quedas.

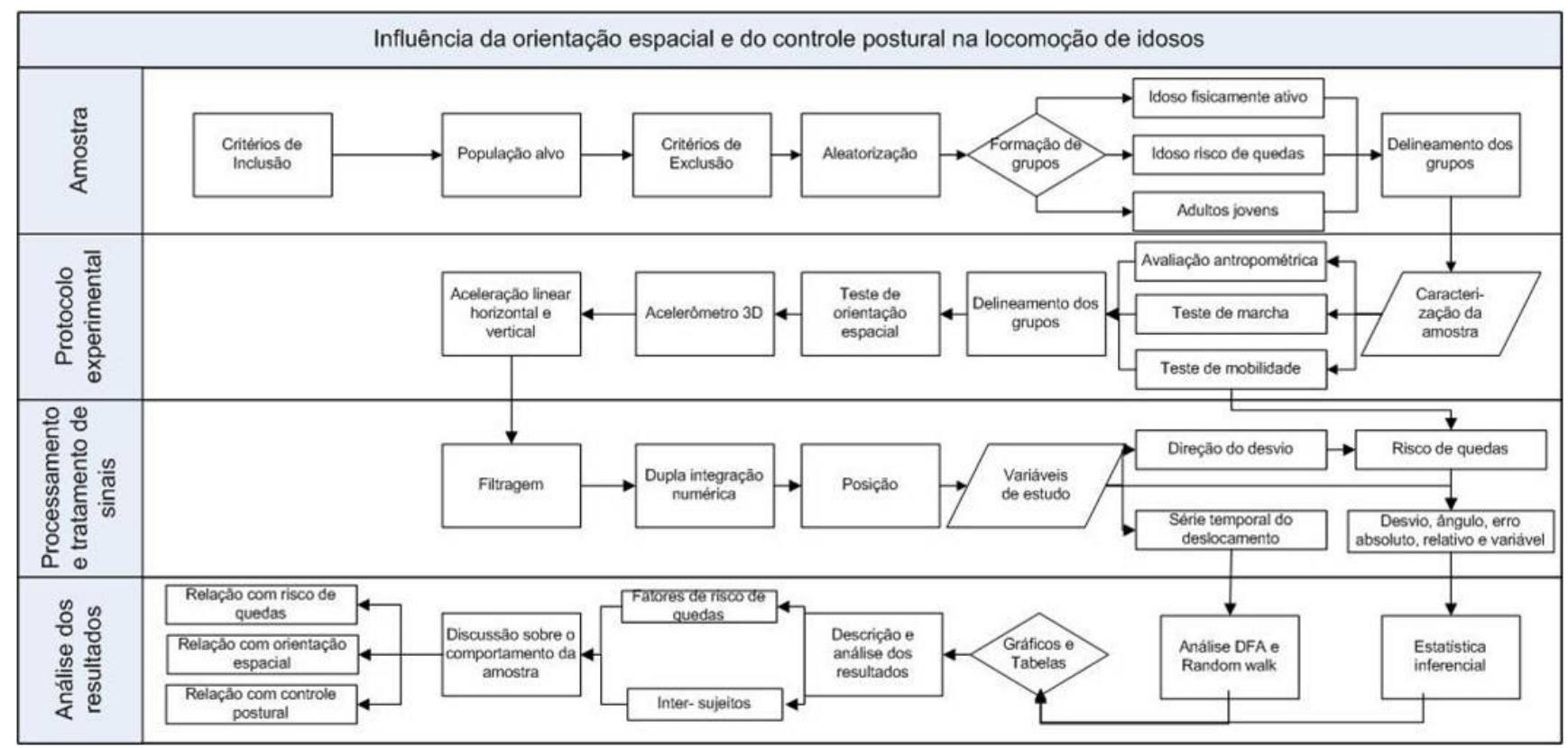

FIGURA 2 - Diagrama de blocos com descrição do protocolo experimental.

\subsection{Instrumentos}

Para este estudo foi usado um acelerômetro 3D (EMG System) que mede a aceleração em três eixos: horizontal (x), vertical (y) e um terceiro eixo perpendicular a esses dois (z). O sistema contém um sensor em forma de mola, com superfície revestida de material polisiliconado, construído sobre uma superfície de silicone. Este sensor estabelece uma resistência contra as forças de aceleração. A deflexão desta estrutura é medida através de um capacitor diferencial. As ondas geradas por esta deflexão são proporcionais à aceleração. 
O sensor capta as variações de voltagem, proporcionalmente à aceleração, com precisão de $\pm 1,7 \mathrm{~g}$. Possui sensibilidade para captar inclinações menores que $1 \mathrm{mg}$, o equivalente a 0,06 graus.

O acelerômetro foi fixado verticalmente nas costas entre as vértebras L1 e L2 ligado ao sistema de aquisição através de um cabo de $30 \mathrm{~m}$ de comprimento que permite o deslocamento na tarefa.

\subsection{Variáveis de estudo}

As variáveis analisadas foram: grupo (idoso $\mathrm{AF}$, idoso $\mathrm{RQ}$, adulto); escore do teste Berg; escore do teste Tinetti e seus subresultados (equilíbrio sentado e em pé; equilíbrio total; teste de marcha Tinetti); média do desvio da direção; variabilidade da média do desvio da direção; antecedente de queda (sim e não); problema de visão (sim e não); labirintite (sim e não); ingestão diária de comprimidos (nada, pouco - até 3 comprimidos, risco - 4 ou mais comprimidos); lateralidade (destro e canhoto); erro absoluto; erro variável; erro constante; média do ângulo do desvio da direção; variabilidade do ângulo do desvio da direção; porcentagem da direção do desvio do alvo; expoente do DFA (detrended flutuation analysis); dimensão fractal do DFA; tempo crítico da análise do random walk; dimensão do componente curto e longo da análise do random walk; coeficiente de Hurst do componente curto e longo da análise random walk.

\subsection{Processamento do sinal}

A partir dos dados obtidos no questionário inicial (ANEXO 1), na avaliação da capacidade funcional (ANEXO 2), no questionário do IPAQ (ANEXO 3 e ANEXO 4) selecionamos aleatoriamente a amostra de acordo com os critérios de inclusão e exclusão de cada grupo. Os grupos foram classificados em: idoso praticante de atividade física (idoso $\mathrm{AF}$ ), idoso com risco de quedas (idoso RQ), adulto.

Com os dados gerados pelos testes Berg (ANEXO 6), Tinetti (ANEXO 7) e marcha Tinetti (ANEXO 8) fizemos a relação com o risco de quedas, para isso, usamos seus respectivos resultados e subresultados. A soma total do Teste Berg é de 52 pontos e seu escore foi obtido dividindo a pontuação de cada sujeito por 52 . A soma total do Teste Tinetti é feita pela soma do teste de equilíbrio (ANEXO 7) com a soma do teste de marcha (ANEXO 8) sendo, portanto, 28 pontos e, seu escore total foi obtido dividindo a soma da pontuação de cada sujeito por 28. Os subresultados do Teste Tinetti foram classificados dessa forma: a soma dos testes 1 , 2, 3, 9 do teste de equilíbrio (ANEXO 7) foi dividida por 16 e classificada como equilíbrio sentado, pois, os testes exigiam equilíbrio sentado; a soma dos testes 4, 5, 6, 7, 8, do teste de equilíbrio (ANEXO 7) foi dividida por 16 e classificada como equilíbrio em pé, pois, os testes exigiam equilíbrio em pé; a soma dos resultados do teste de marcha (ANEXO 8) foi dividida por 12 e classificada como teste de marcha.

Para fazer a relação dos fatores de risco de quedas acidentais com os testes de mobilidade e marcha aplicados classificamos os sujeitos a partir do questionário inicial (ANEXO 1) como: antecedente de queda 
(sim e não); problema de visão (sim e não); labirintite (sim e não); ingestão diária de comprimidos (nada, pouco - até 3 comprimidos, risco - 4 ou mais comprimidos) e lateralidade (destro e canhoto).

A medida do veering foi feita com a medida no plano horizontal da distância do alvo à posição final de cada tentativa de cada sujeito (Figura 1). Calculamos a média e o desvio padrão da soma das 10 tentativas de olhos fechados de cada sujeito.para obter a média do desvio da direção e variabilidade da média do desvio da direção. As medidas à esquerda do alvo foram classificadas com número negativo e as medidas à direita do alvo com número positivo. Calculamos o erro absoluto, que é o desvio absoluto da trajetória linear ignorando a direção do desvio; o erro variável, que é a variância da média do erro constante; e o erro constante (Vuillerme et al., 2002), pelas seguintes fórmulas:

$$
\begin{aligned}
& \text { Erro absoluto }=\underline{\Sigma_{i}} \frac{\left|x_{i}-A\right|}{n} \\
& \text { Erro variável }=\frac{\sqrt{\sum_{i}\left(x_{i}-x^{-}\right)^{2}}}{n} \\
& \text { Erro constante }=\frac{\Sigma_{i}\left(x_{i}-A\right)}{n}
\end{aligned}
$$

em que $\mathrm{A}=$ alvo ou referência, no caso $\mathrm{A}=0 ; \mathrm{x}=$ soma das 10 tentativas de olhos fechados de cada sujeito; $\mathrm{n}=$ número de tentativas, no caso $\mathrm{n}=10$.

Calculamos também média do ângulo do desvio e o desvio padrão do ângulo do desvio 10 tentativas de olhos fechados de cada sujeito. O ângulo do desvio foi calculado para cada tentativa de cada sujeito pela fórmula:

$$
\alpha=\operatorname{arctg} \underline{\mathrm{D}}_{\mathrm{r}}
$$

em que $\mathrm{D}=$ a medida do desvio de cada tentativa; $\mathrm{r}=$ distância pretendida, no caso $\mathrm{r}=15$.

Para quantificar a direção dos desvios calculamos a porcentagem da direção do desvio do alvo de cada sujeito nas dez tentativas de olhos fechados.

$\mathrm{O}$ acelerômetro fornece os dados da aceleração em cada instante de tempo e, integrando esse sinal uma vez podemos obter a velocidade, integrando mais uma vez podemos obter as coordenadas da posição nos eixos $\mathrm{x}, \mathrm{y}, \mathrm{z}$. Com esses dados fizemos a análise da trajetória durante o deslocamento, através da análise do DFA (detrended flutuation analysis) e do Random walk analisys. Essa operação foi feita em uma rotina dentro do ambiente Matlab (ANEXO 9 e ANEXO 10).

Com o Random walk analisamos o sistema em duas etapas, divididas pelo tempo crítico. A primeira fase que se caracteriza por apresentar a maior atividade estocástica, com suas variáveis: dimensão do 
componente curto (DST) e coeficiente de Hurst do componente curto (HST). A segunda fase se caracteriza por apresentar menor atividade estocástica, com suas variáveis: dimensão do componente longo (DLT) e coeficiente de Hurst do componente longo (HLT). O coeficiente de Hurst refelte o nível de atividade estocástica do deslocamento, ou seja, da oscilação. Se o coeficiente de Hurst for maior que 0,5, o processo estocástico é correlacionado positivamente, ou seja, o aumento ou a diminuição da tendência no passado implica no aumento ou na diminuição da tendência no futuro. Se o coeficiente de Hurst for menor que 0,5 , o processo estocástico é correlacionado negativamente, ou seja, o passado e o futuro são incrementos negativamente correlacionados.

Com a análise do DFA e a do Random walk podemos observar o comportamento das suas variáveis nas direções ântero- posterior e médio- lateral.

As variáveis tratadas foram então correlacionadas por estatística inferencial no programa Statistica'99.

Foi usada a análise de variância (ANOVA) de um fator para correlacionar: grupo,testes de risco de quedas e desvio da direção; fatores de risco de quedas, testes de risco de quedas e desvio da direção; grupo, veering.

Foi usada a análise de variância (ANOVA) de dois fatores para correlacionar: grupo e lado (porcentagem da direção do desvio do alvo- esquerda, direita, alvo); grupo e direção (deslocamento ântero- posterior e médio- lateral).

A associação da análise da trajetória da tarefa com os testes que indicam os fatores de risco de quedas acidentais foi feita pelo método de regressão múltipla no programa OriginPro"8.

\section{RESULTADOS}

A seguir apresentaremos os resultados do efeito do grupo nos testes de risco de quedas e no desvio da direção; do efeito dos fatores de risco de quedas nos testes de risco de quedas e no desvio da direção; do efeito do grupo no veering; do efeito do grupo e da variabilidade da direção na trajetória; e do efeito dos testes de risco de quedas na trajetória.

\subsection{Efeito do grupo nos testes de risco de quedas e no desvio da direção}

Foi usada a análise de variância (ANOVA) de um fator para verificar o efeito do grupo nos testes analisados. A variável independente chamada grupo foi dividida em: idoso praticante de atividade física (idoso $\mathrm{AF}$ ), idoso com risco de quedas (idoso RQ), adulto. As variáveis dependentes são: testes Berg e Tinetti e subresultados (equilíbrio sentado e em pé; equilíbrio total; teste de marcha Tinetti; escore total do teste Tinetti); média do desvio da direção; e variabilidade da média do desvio da direção.

Os resultados médios e os respectivos desvios-padrão do teste Berg estão na TABELA 1. O grupo afetou o resultado do teste Berg $\left(\mathrm{F}_{(2,63)}=11,5, \mathrm{p}=0,0001\right)$. $\mathrm{O}$ teste post hoc Tukey HSD indicou que o grupo adulto apresentou o maior resultado no teste Berg $(\mathrm{p}<0,01)$. Os resultados médios e os desvios-padrão do teste 
Tinetti estão na TABELA 2. Em relação ao teste Tinetti, não observamos o efeito do grupo para o equilíbrio sentado $\left(\mathrm{F}_{(2,63)}=0,7, \mathrm{p}=0,48\right)$, em pé $\left(\mathrm{F}_{(2,63)}=2,2, \mathrm{p}=0,11\right)$ e nem para o equilíbrio total $\left(\mathrm{F}_{(2,63)}=2,1, \mathrm{p}=0,12\right)$, e encontramos efeito do grupo para o equilíbrio na marcha $\left(\mathrm{F}_{(2,63)}=11,3, \mathrm{p}=0,0001\right)$. $\mathrm{O}$ teste post hoc Tukey HSD indicou que os grupos adulto e idoso AF apresentaram os maiores resultados no teste de marcha $(\mathrm{p}<0,01)$. $\mathrm{O}$ grupo afetou o resultado do escore total do teste Tinetti $\left(\mathrm{F}_{(2,63)}=11,0, \mathrm{p}=0,0001\right)$. $\mathrm{O}$ teste post hoc Tukey HSD indicou que os grupos adulto e idoso AF apresentaram os maiores escores do teste Tinetti $(\mathrm{p}<0,01)$. Os resultados médios e os respectivos desvios-padrão do teste de orientação espacial estão na TABELA 3. Em relação ao desvio do alvo, usamos a ANOVA de um fator para verificar o efeito do grupo nas variáveis associadas ao desvio. A média do desvio $\left(\mathrm{F}_{(2,63)}=0,6, \mathrm{p}=0,51\right)$ da direção não foi afetada pelo grupo. A variabilidade do desvio médio da direção foi afetada pelo grupo $\left(\mathrm{F}_{(2,63)}=4,6, \mathrm{p}=0,01\right)$. O teste post hoc Tukey HSD indicou que o grupo idoso RQ apresentou maior variabilidade do desvio da direção que o grupo adulto e o grupo idoso $\mathrm{AF}(\mathrm{p}=0,03)$.

TABELA 1: Valores médios e desvio padrão do teste Berg de equilíbrio para os grupos: idoso atividade física (idoso AF), idoso risco de quedas (idoso RQ) e adulto.

\begin{tabular}{lcc}
\hline Grupo & Equilíbrio Sentado & $\mathrm{N}$ \\
\hline Idoso AF & $0,98 \pm 0,05$ & 27 \\
Idoso RQ & $0,97 \pm 0,06$ & 12 \\
Adulto & $1,00 \pm 0,01^{*}$ & 27 \\
\hline
\end{tabular}

* Significante em $\mathrm{p}<0,05$.

TABELA 2: Valores médios e desvio padrão do teste Tinetti para equilíbrio sentado, equilíbrio em pé, equilíbrio total, marcha, escore total para os grupos: idoso atividade física (idoso $\mathrm{AF}$ ), idoso risco de quedas (idoso RQ) e adulto.

\begin{tabular}{lcccccc}
\hline Grupo & $\begin{array}{c}\text { Equilíbrio } \\
\text { Sentado }\end{array}$ & $\begin{array}{c}\text { Equilíbrio em } \\
\text { pé }\end{array}$ & $\begin{array}{c}\text { Equilíbrio } \\
\text { total }\end{array}$ & Marcha & $\begin{array}{c}\text { Escore } \\
\text { total }\end{array}$ & $\mathrm{N}$ \\
\hline Idoso AF & $0,43 \pm 0,03$ & $0,55 \pm 0,05$ & $0,98 \pm 0,05$ & $0,96 \pm 0,07^{*}$ & $0,97 \pm 0,04^{*}$ & 27 \\
Idoso RQ & $0,43 \pm 0,02$ & $0,54 \pm 0,04$ & $0,97 \pm 0,06$ & $0,83 \pm 0,22$ & $0,91 \pm 0,11$ & 12 \\
Adulto & $0,44 \pm 0,01$ & $0,56 \pm 0,00$ & $1,00 \pm 0,01$ & $1,00 \pm 0,00^{*}$ & $1,00 \pm 0,01^{*}$ & 27 \\
\hline
\end{tabular}

* Significante em $\mathrm{p}<0,05$. 
TABELA 3: Valores médios e desvio padrão do desvio e variabilidade do teste de orientação espacial de olhos fechados para os grupos idoso atividade física (idoso AF), idoso risco de quedas (idoso RQ), adulto. Os valores positivos indicam o desvio para a direita e os valores negativos o desvio para a esquerda.

\begin{tabular}{cccc}
\hline Grupo & Desvio médio & Variabilidade do desvio & $\mathrm{n}$ \\
\hline Idoso AF & $0,46 \pm 1,71$ & $2,25 \pm 0,84$ & 27 \\
Idoso RQ & $0,69 \pm 5,21$ & $2,88 \pm 1,88^{*}$ & 12 \\
Adulto & $-0,22 \pm 1,56$ & $1,77 \pm 0,75$ & 27 \\
\hline
\end{tabular}

* Significante em $\mathrm{p}<0,05$.

\subsection{Efeito dos fatores de risco de quedas nos testes de risco de quedas e no desvio da direção}

A seguir apresentaremos resultados da associação dos fatores de risco de quedas acidentais com os testes aplicados.

Foi usado análise de variância (ANOVA) de um fator para verificar o efeito das variáveis independentes nas variáveis dependentes analisadas. As variáveis independentes são: antecedente de queda ( pouco - até 3 comprimidos, risco - 4 ou mais comprimidos); lateralidade (destro e canhoto). As variáveis dependentes são: teste Berg, e Tinetti e seus subresultados (equilíbrio sentado e em pé; equilíbrio total; teste demarcha Tinetti; escore total do teste Tinetti); média do desvio da direção; variabilidade da média do desvio da direção.

Foi usada a ANOVA de um fator para verificar o efeito do histórico de quedas nos testes analisados. Os resultados médios e os respectivos desvios-padrão do teste Berg estão na TABELA 4. O teste Berg não foi afetado pelo histórico de queda $\left(\mathrm{F}_{(1,64)}=3,2, \mathrm{p}=0,07\right)$. Os resultados médios e os desvios-padrão do teste Tinetti estão na TABELA 5. Sobre o teste Tinetti, o histórico de queda não afetou o equilíbrio sentado $\left(\mathrm{F}_{(1,64)}=0,9\right.$, $\mathrm{p}=0,33)$, em pé $\left(\mathrm{F}_{(1,64)}=2,0, \mathrm{p}=0,15\right)$ e nem o equilíbrio total $\left(\mathrm{F}_{(1,64)}=2,8, \mathrm{p}=0,09\right)$, e tão pouco o teste de marcha $\left(F_{(1,64)}=3,4, p=0,06\right)$. Entretanto, o escore total do teste Tinetti foi afetado pelo histórico de quedas $\left(F_{(1,64)}=4,8\right.$, p=0,03). O teste post hoc Tukey HSD não indicou o nível da diferença entre ter ou não ter sofrido queda. Os resultados médios e os desvios-padrão do teste de orientação espacial estão na TABELA 6. Em relação ao desvio do alvo, o histórico de quedas não afetou o desvio médio $\left(\mathrm{F}_{(1,64)}=3,8, \mathrm{p}=0,05\right)$ e sua variabilidade $\left(F_{(1,64)}=0,1, p=0,75\right)$. $O$ teste post hoc Tukey HSD não indicou o nível da diferença estatística entre ter ou não ter sofrido queda. 
TABELA 4: Valores médios e desvio padrão do teste Berg de equilíbrio dos sujeitos sem antecedente de queda (não) e dos sujeitos com antecedente de queda (sim).

\begin{tabular}{ccc}
\hline Histórico de quedas & Teste Berg & N \\
\hline Não & $0,98 \pm 0,04$ & 55 \\
Sim & $0,96 \pm 0,05$ & 11 \\
\hline
\end{tabular}

TABELA 5: Valores médios e desvio padrão do teste Tinetti para equilíbrio sentado, equilíbrio em pé, equilíbrio total, marcha, escore total dos sujeitos sem antecedente de queda (não) e dos sujeitos com antecedente de queda (sim).

\begin{tabular}{ccccccc}
\hline $\begin{array}{c}\text { Histórico } \\
\text { de quedas }\end{array}$ & $\begin{array}{c}\text { Equilíbrio } \\
\text { sentado }\end{array}$ & $\begin{array}{c}\text { Equilíbrio em } \\
\text { pé }\end{array}$ & $\begin{array}{c}\text { Equilíbrio } \\
\text { total }\end{array}$ & Marcha & $\begin{array}{c}\text { Escore } \\
\text { total }\end{array}$ & $\mathrm{N}$ \\
\hline Não & $0,43 \pm 0,02$ & $0,56 \pm 0,03$ & $0,99 \pm 0,04$ & $0,96 \pm 0,10$ & $0,98 \pm 0,05$ & 55 \\
Sim & $0,43 \pm 0,03$ & $0,54 \pm 0,04$ & $0,97 \pm 0,06$ & $0,89 \pm 0,16$ & $0,94 \pm 0,09$ & 11 \\
\hline
\end{tabular}

TABELA 6: Valores médios e desvio padrão do desvio e sua variabilidade do teste de orientação espacial de olhos fechados dos sujeitos com (sim) e sem antecedente de queda (não). Os valores positivos indicam o desvio para a direita e os valores negativos o desvio para a esquerda.

\begin{tabular}{cccc}
\hline Histórico de quedas & Média do desvio & Variabilidade do desvio & $\mathrm{N}$ \\
\hline Não & $-0,05 \pm 2,39$ & $2,19 \pm 1,15$ & 55 \\
Sim & $1,61 \pm 3,38$ & $2,07 \pm 1,03$ & 11 \\
\hline
\end{tabular}

Foi usada a ANOVA de um fator para verificar o efeito de ter ou não ter algum problema de visão nos testes analisados. Os resultados médios e os respectivos desvios-padrão do teste Berg estão na TABELA 7. O teste Berg não foi afetado pelo problema de visão $\left(\mathrm{F}_{(1,64)}=1,1, \mathrm{p}=0,29\right)$. Os resultados médios e os respectivos desvios-padrão do teste Tinetti estão na TABELA 8. Sobre o teste Tinetti, não houve efeito do problema de visão no equilíbrio sentado $\left(\mathrm{F}_{(1,64)}=0,7, \mathrm{p}=0,39\right)$ ou em pé $\left(\mathrm{F}_{(1,64)}=0,1, \mathrm{p}=0,74\right)$, e nem no equilíbrio total $\left(\mathrm{F}_{(1,64)}=0,4, \mathrm{p}=0,49\right)$. Entretanto, houve efeito do problema de visão na marcha $\left(\mathrm{F}_{(1,64)}=5,8, \mathrm{p}=0,01\right)$ e no escore total de Tinetti $\left(\mathrm{F}_{(1,64)}=4,9, \mathrm{p}=0,03\right)$. O teste post hoc Tukey HSD indicou que o teste de marcha de Tinetti e o escore total de Tinetti foram maiores nos indivíduos sem problema de visão $(\mathrm{p}<0,03)$. Os resultados médios e os respectivos desvios-padrão do teste de orientação espacial estão na TABELA 9. Em relação ao desvio do alvo, o problema de visão não afetou o desvio médio $\left(\mathrm{F}_{(1,64)}=0,4, \mathrm{p}=0,51\right)$, mas afetou a variabilidade do desvio da direção $\left(\mathrm{F}_{(1,64)}=4,7, \mathrm{p}=0,03\right)$. O teste post hoc Tukey HSD indicou que a variabilidade do desvio foi maior nas pessoas com problema de visão $(\mathrm{p}=0,03)$. 
TABELA 7: Valores médios e desvio padrão do teste Berg de equilíbrio dos sujeitos com (sim) e sem problemas de visão (não).

\begin{tabular}{ccc}
\hline Problemas de visão & Media e Dp & N \\
\hline Sim & $0,97 \pm 0,04$ & 31 \\
Não & $0,98 \pm 0,04$ & 35 \\
\hline
\end{tabular}

TABELA 8: Valores médios e desvio padrão do teste Tinetti para equilíbrio sentado, equilíbrio em pé, equilíbrio total, marcha, escore total dos sujeitos com problemas de visão (sim) e dos sujeitos sem problemas de visão (não).

\begin{tabular}{ccccccc}
\hline $\begin{array}{c}\text { Problemas } \\
\text { de visão }\end{array}$ & $\begin{array}{c}\text { Equilíbrio } \\
\text { sentado }\end{array}$ & $\begin{array}{c}\text { Equilíbrio em } \\
\text { pé }\end{array}$ & $\begin{array}{c}\text { Equilíbrio } \\
\text { total }\end{array}$ & Marcha & $\begin{array}{c}\text { Escore } \\
\text { total }\end{array}$ & $\mathrm{N}$ \\
\hline Sim & $0,43 \pm 0,02$ & $0,55 \pm 0,03$ & $0,98 \pm 0,04$ & $0,92 \pm 0,16$ & $0,95 \pm 0,08$ & 31 \\
Não & $0,43 \pm 0,02$ & $0,56 \pm 0,04$ & $0,99 \pm 0,05$ & $0,98 \pm 0,04^{*}$ & $0,99 \pm 0,04^{*}$ & 35 \\
\hline
\end{tabular}

* Significante em $\mathrm{p}<0,05$.

TABELA 9: Desvio médio e variabilidade do teste de orientação espacial de olhos fechados dos sujeitos com (sim) e sem problemas de visão (não). Os valores positivos indicam o desvio para a direita e os valores negativos o desvio para a esquerda.

\begin{tabular}{cccc}
\hline Problemas de visão & Média do desvio & Variabilidade do desvio & $\mathrm{N}$ \\
\hline Sim & $0,45 \pm 3,51$ & $2,48 \pm 1,35^{*}$ & 31 \\
Não & $0,02 \pm 1,47$ & $1,89 \pm 0,80$ & 35 \\
\hline
\end{tabular}

* Significante em $\mathrm{p}<0,05$.

Foi usada a ANOVA de um fator para verificar o efeito da labirintite nos testes analisados. Os resultados médios e os respectivos desvios-padrão do teste Berg estão na TABELA 10. A labirintite afetou o resultado do teste Berg $\left(\mathrm{F}_{(1,64)}=10,9, \mathrm{p}=0,001\right)$. O teste post hoc Tukey HSD indicou maior resultado no teste Berg nos indivíduos que não possuíam labirintite $(\mathrm{p}<0,01)$. Os resultados médios e os desvios-padrão do teste Tinetti estão na TABELA 11. Sobre o teste Tinetti, a labirintite afetou o equilíbrio em pé $\left(\mathrm{F}_{(1,64)}=7,8\right.$, $\mathrm{p}=0,006)$, total $\left(\mathrm{F}_{(1,64)}=7,2, \mathrm{p}=0,008\right)$, a marcha $\left(\mathrm{F}_{(1,64)}=10,6, \mathrm{p}=0,001\right)$ e o escore total $\left(\mathrm{F}_{(1,64)}=14,7, \mathrm{p}=0,0003\right)$, mas não afetou o equilíbrio sentado $\left(\mathrm{F}_{(1,64)}=0,5, \mathrm{p}=0,45\right)$. $\mathrm{O}$ teste post hoc Tukey HSD indicou maiores resultados para os indivíduos que não possuíam labirintite nos testes de equilíbrio em pé $(\mathrm{p}<0,01)$, marcha $(\mathrm{p}<0,01)$ e no escore total $(\mathrm{p}<0,01)$. Não foi possível detectar o nível da diferença estatística entre ter ou não ter labirintite no equilíbrio total. Os resultados médios e os desvios-padrão do teste de orientação espacial estão na Tabela 12. Em relação ao desvio da direção, a labirintite não afetou o desvio médio $\left(\mathrm{F}_{(1,64)}=1,9\right.$, $\mathrm{p}=0,16)$ e sua variabilidade $\left(\mathrm{F}_{(1,64)}=0,5, \mathrm{p}=0,46\right)$. 
TABELA 10: Valores médios e desvio padrão do teste Berg de equilíbrio dos sujeitos sem labirintite (não) e com labirintite (sim).

\begin{tabular}{ccc}
\hline Labirintite & Media e Dp & N \\
\hline Não & $0,98 \pm 0,03^{*}$ & 61 \\
Sim & $0,93 \pm 0,06$ & 05 \\
\hline
\end{tabular}

* Significante em $\mathrm{p}<0,05$.

TABELA 11: Valores médios e desvio padrão do teste Tinetti para equilíbrio sentado, equilíbrio em pé, equilíbrio total, marcha, escore total dos sujeitos sem labirintite (não) e com labirintite (sim).

\begin{tabular}{ccccccc}
\hline Labirintite & $\begin{array}{c}\text { Equilíbrio } \\
\text { sentado }\end{array}$ & $\begin{array}{c}\text { Equilíbrio em } \\
\text { pé }\end{array}$ & $\begin{array}{c}\text { Equilíbrio } \\
\text { total }\end{array}$ & Marcha & $\begin{array}{c}\text { Escore } \\
\text { total }\end{array}$ & $\mathrm{N}$ \\
\hline Não & $0,43 \pm 0,02$ & $0,56 \pm 0,03^{*}$ & $0,99 \pm 0,04$ & $0,96 \pm 0,10^{*}$ & $0,98 \pm 0,05^{*}$ & 61 \\
Sim & $0,43 \pm 0,03$ & $0,51 \pm 0,05$ & $0,94 \pm 0,08$ & $0,80 \pm 0,21$ & $0,88 \pm 0,11$ & 05 \\
\hline
\end{tabular}

* Significante em $\mathrm{p}<0,05$.

TABELA 12: Desvio médio e variabilidade do teste de orientação espacial de olhos fechados dos sujeitos sem labirintite (não) e com labirintite (sim). Os valores positivos indicam o desvio para a direita.

\begin{tabular}{cccc}
\hline Labirintite & Média do desvio & Variabilidade do desvio & $\mathrm{N}$ \\
\hline Não & $0,09 \pm 2,09$ & $2,14 \pm 0,95$ & 61 \\
Sim & $1,79 \pm 6,57$ & $2,52 \pm 2,59$ & 05 \\
\hline
\end{tabular}

Foi usada a ANOVA de um fator para verificar o efeito da quantidade de comprimidos ingeridos diariamente nos testes analisados. Os resultados médios e os desvios-padrão do teste Berg estão na TABELA 13. A quantidade de comprimidos ingeridos diariamente afetou o teste $B e r g\left(F_{(2,63)}=9,0, p=0,0004\right)$. $O$ teste post hoc Tukey HSD indicou o maior resultado no teste Berg nos indivíduos que não ingeriam comprimidos $(\mathrm{p}<0,04)$. Os resultados médios e os desvios-padrão do teste Tinetti estão na TABELA 14. Sobre o teste Tinetti, a quantidade de comprimidos não afetou o equilíbrio sentado $\left(\mathrm{F}_{(2,63)}=2,3, \mathrm{p}=0,09\right)$, em pé $\left(\mathrm{F}_{(2,63)}=1,9\right.$, $\mathrm{p}=0,15)$, o equilíbrio total $\left(\mathrm{F}_{(2,63)}=2,8, \mathrm{p}=0,06\right)$ e nem escore total de Tinetti $\left(\mathrm{F}_{(2,63)}=10,0, \mathrm{p}=0,0002\right)$, mas afetou a marcha $\left(\mathrm{F}_{(2,63)}=11,3, \mathrm{p}=0,0001\right)$. O teste post hoc Tukey HSD indicou maiores resultados nos indivíduos que não ingeriam comprimidos no teste de marcha de Tinetti $(\mathrm{p}<0,01)$. Os resultados médios e os desviospadrão do teste de orientação espacial estão na TABELA 15. Em relação ao desvio do alvo, a quantidade de comprimidos ingeridos não afetou o desvio médio $\left(\mathrm{F}_{(2,63)}=0,9, \mathrm{p}=0,38\right)$, mas afetou a variabilidade $\left(\mathrm{F}_{(2,63)}=4,2\right.$, $\mathrm{p}=0,01)$. O teste post hoc Tukey HSD não indicou o nível da diferença entre número de comprimidos ingeridos diariamente na variabilidade do desvio. 
TABELA 13: Valores médios e desvio padrão do teste Berg de equilíbrio de acordo com a ingestão diária de medicamentos: nada, pouco (até 3 comprimidos) e risco (4 ou mais comprimidos).

\begin{tabular}{ccc}
\hline Ingestão remédio & Equilíbrio Sentado & $\mathrm{N}$ \\
\hline Nada & $0,99 \pm 0,02^{*}$ & 33 \\
Pouco & $0,97 \pm 0,04$ & 24 \\
Risco & $0,94 \pm 0,06$ & 9 \\
\hline
\end{tabular}

$*$ Significante em $\mathrm{p}<0,05$.

TABELA 14: Valores médios e desvio padrão do teste Tinetti para equilíbrio sentado, equilíbrio em pé, equilíbrio total, marcha, escore total de acordo com a ingestão diária de remédio: nada, pouco (até 3 comprimidos), risco (4 ou mais comprimidos).

\begin{tabular}{ccccccc}
\hline $\begin{array}{c}\text { Ingestão } \\
\text { remédio }\end{array}$ & $\begin{array}{c}\text { Equilíbrio } \\
\text { sentado }\end{array}$ & $\begin{array}{c}\text { Equilíbrio em } \\
\text { pé }\end{array}$ & $\begin{array}{c}\text { Equilíbrio } \\
\text { total }\end{array}$ & Marcha & $\begin{array}{c}\text { Escore } \\
\text { total }\end{array}$ & $\mathrm{N}$ \\
\hline Nada & $0,44 \pm 0,01$ & $0,56 \pm 0,00$ & $1,00 \pm 0,01$ & $0,99 \pm 0,03^{*}$ & $1,00 \pm 0,01$ & 33 \\
Pouco & $0,42 \pm 0,03$ & $0,55 \pm 0,06$ & $0,97 \pm 0,07$ & $0,94 \pm 0,08$ & $0,96 \pm 0,06$ & 24 \\
Risco & $0,44 \pm 0,00$ & $0,54 \pm 0,03$ & $0,98 \pm 0,03$ & $0,81 \pm 0,25$ & $0,91 \pm 0,12$ & 9 \\
\hline
\end{tabular}

* Significante em $\mathrm{p}<0,05$.

TABELA 15: Desvio médio e variabilidade do teste de orientação espacial de olhos fechados de acordo com a ingestão diária de medicamentos: nada, pouco (até 3 comprimidos), risco (4 ou mais comprimidos). Os valores positivos indicam o desvio para a direita e os negativos o desvio para a esquerda.

\begin{tabular}{cccc}
\hline Ingestão remédio & Média do desvio & Variabilidade do desvio & $\mathrm{N}$ \\
\hline Nada & $-0,14 \pm 1,57$ & $1,85 \pm 0,84$ & 33 \\
Pouco & $0,82 \pm 2,01$ & $2,29 \pm 0,78$ & 24 \\
Risco & $-0,05 \pm 5,72$ & $3,00 \pm 2,12$ & 9 \\
\hline
\end{tabular}

Foi usada a ANOVA de um fator para verificar o efeito da lateralidade (ser destro ou canhoto) nos testes analisados. Os resultados médios e os desvios-padrão do teste Berg estão na TABELA 16. A lateralidade não afetou o resultado do teste $\operatorname{Berg}\left(\mathrm{F}_{(1,64)}=0,31, \mathrm{p}=0,57\right)$. Os resultados médios e os desvios-padrão do teste Tinetti estão na TABELA 17. Sobre o teste Tinetti, a lateralidade não afetou o equilíbrio sentado $\left(\mathrm{F}_{(1,64)}=0,3\right.$, $\mathrm{p}=0,53)$, em pé $\left(\mathrm{F}_{(1,64)}=0,06, \mathrm{p}=0,80\right)$, equilíbrio total $\left(\mathrm{F}_{(1,64)}=0,008, \mathrm{p}=0,92\right)$, o teste de marcha $\left(\mathrm{F}_{(1,64)}=3,0\right.$, $\mathrm{p}=0,08)$ e nem o escore total $\left(\mathrm{F}_{(1,64)}=1,8, \mathrm{p}=0,18\right)$. Os resultados médios e os desvios-padrão do teste de orientação espacial estão na TABELA 18. Em relação ao desvio da direção, a lateralidade também não afetou o desvio médio $\left(\mathrm{F}_{(1,64)}=2,2, \mathrm{p}=0,14\right)$ e sua variabilidade $\left(\mathrm{F}_{(1,64)}=2,2, \mathrm{p}=0,13\right)$. 
TABELA 16: Valores médios e desvio padrão do teste Berg de equilíbrio dos sujeitos de acordo com a lateralidade: destro, canhoto.

\begin{tabular}{ccc}
\hline Lateralidade & Media e Dp & N \\
\hline Destro & $0,98 \pm 0,04$ & 61 \\
Canhoto & $0,97 \pm 0,07$ & 5 \\
\hline
\end{tabular}

TABELA 17: Valores médios e desvio padrão do teste Tinetti para equilíbrio sentado, equilíbrio em pé, equilíbrio total, marcha, escore total dos sujeitos de acordo com a lateralidade destra ou canhota.

\begin{tabular}{ccccccc}
\hline Lateralidade & $\begin{array}{c}\text { Equilíbrio } \\
\text { sentado }\end{array}$ & Equilíbrio em pé & $\begin{array}{c}\text { Equilíbrio } \\
\text { total }\end{array}$ & Marcha & $\begin{array}{c}\text { Escore } \\
\text { total }\end{array}$ & $\mathrm{N}$ \\
\hline Destro & $0,43 \pm 0,02$ & $0,55 \pm 0,04$ & $0,99 \pm 0,04$ & $0,96 \pm 0,10$ & $0,97 \pm 0,06$ & 61 \\
Canhoto & $0,44 \pm 0,00$ & $0,55 \pm 0,03$ & $0,99 \pm 0,03$ & $0,87 \pm 0,22$ & $0,94 \pm 0,11$ & 5 \\
\hline
\end{tabular}

TABELA 18: Desvio médio e variabilidade do teste de orientação espacial de olhos fechados dos sujeitos destros e canhotos. Os valores positivos indicam o desvio para a direita.

\begin{tabular}{rccc}
\hline Lateralidade & Média do desvio & Variabilidade do desvio & $\mathrm{N}$ \\
\hline Destro & $0,09 \pm 2,54$ & $2,22 \pm 1,12$ & 61 \\
Canhoto & $1,89 \pm 3,33$ & $1,45 \pm 0,96$ & 5 \\
\hline
\end{tabular}

\subsection{Efeito do grupo no veering}

Para saber se grupos selecionados sofreram veering durante a tarefa calculamos as medidas de erro absoluto, de erro variável, de erro constante. Calculamos também o ângulo do desvio e a porcentagem da direção do desvio do alvo de cada sujeito nas dez tentativas de olhos fechados.

Foi usada a análise de variância (ANOVA) de um fator para verificar o efeito do grupo no veering (desvio do alvo). A variável independente chamada grupo foi dividida em: idoso praticante de atividade física (idoso AF), idoso com risco de quedas (idoso RQ), adulto. As variáveis dependentes são: erro absoluto, erro variável, erro constante, média do ângulo do desvio, variabilidade do ângulo do desvio.

Os resultados médios e os respectivos desvios-padrão do erro absoluto, do erro variável, do erro constante, da média do ângulo do desvio e da variabilidade do ângulo do desvio estão na TABELA 19. O grupo afetou o resultado do erro absoluto $\left(\mathrm{F}_{(2,63)}=16,64, \mathrm{p} \leq 0,0001\right)$ e do erro variável $\left(\mathrm{F}_{(2,63)}=4,5, \mathrm{p}=0,013\right)$ mas não afetou o erro constante $\left(\mathrm{F}_{(2,63)}=0,62, \mathrm{p}=0,53\right)$. $\mathrm{O}$ teste post hoc Tukey HSD indicou que o grupo idoso RQ apresentou o maior resultado no erro absoluto $(p=0,0001)$ e no erro variável $(p=0,03)$. Em relação ao 
ângulo do desvio, o grupo não afetou o resultado da média do ângulo do desvio $\left(\mathrm{F}_{(2,63)}=0,85, \mathrm{p}=0,42\right)$ mas afetou a variabilidade $\left(\mathrm{F}_{(2,63)}=3,94, \mathrm{p}=0,024\right)$. $\mathrm{O}$ teste post hoc Tukey HSD não indicou que o grupo que apresentou maior variabilidade.

TABELA 19: Valores médios e desvio padrão das medidas de erro absoluto, de erro variável, de erro constante, da média do ângulo do desvio e da variabilidade do ângulo do desvio (em graus) para os grupos: idoso atividade física (idoso $\mathrm{AF}$ ), idoso risco de quedas (idoso $\mathrm{RQ}$ ) e adulto.

\begin{tabular}{lcccccc}
\hline Grupo & $\begin{array}{c}\text { Erro } \\
\text { absoluto }\end{array}$ & $\begin{array}{c}\text { Erro } \\
\text { variável }\end{array}$ & $\begin{array}{c}\text { Erro } \\
\text { constante }\end{array}$ & $\begin{array}{c}\text { Média do } \\
\text { ângulo do } \\
\text { desvio }\left(^{\circ}\right)\end{array}$ & $\begin{array}{c}\text { Variabilidade } \\
\text { do ângulo do } \\
\text { desvio }\left({ }^{\circ}\right)\end{array}$ & N \\
\hline Idoso AF & $2,15 \pm 0,88$ & $2,13 \pm 0,80$ & $0,45 \pm 1,71$ & $1,71 \pm 6,30$ & $8,02 \pm 2,86$ & 27 \\
Idoso RQ & $4,59 \pm 2,93^{*}$ & $2,72 \pm 1,77^{*}$ & $0,64 \pm 5,18$ & $2,86 \pm 17,19$ & $9,74 \pm 5,73$ & 12 \\
Adulto & $1,66 \pm 0,96$ & $1,67 \pm 0,71$ & $-0,21 \pm 1,55$ & $-0,57 \pm 5,73$ & $6,30 \pm 2,29$ & 27 \\
\hline
\end{tabular}

* Significante em $\mathrm{p}<0,05$.

Para saber consistência da direção do desvio do alvo por grupo calculamos em porcentagem a direção de cada sujeito nas dez tentativas de olhos fechados. Foi usado análise a ANOVA de dois fatores para verificar o efeito da variável independente (porcentagem de desvio do alvo de cada sujeito) nas variáveis dependentes grupo (idoso praticante de atividade física, idoso com risco de quedas, adulto) e lado (deslocamento para a direita do alvo, deslocamento para a esquerda do alvo e alvo). A variável dependente chamada de lado foi calculada com base em cada uma das dez tentativas de deslocamento de olhos fechados de cada sujeito.

Os resultados médios e os desvios-padrão porcentagem de desvio do alvo estão na TABELA 20. O

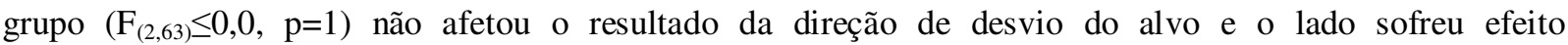
$\left(F_{(2,126)}=40,42, p \leq 0,00001\right)$. O teste post hoc Tukey HSD não indicou qual o grupo que foi mais consistente na direção do desvio do alvo.

TABELA 20: Valores médios e desvio padrão da direção do desvio do alvo em porcentagem (\%) para grupos: idoso atividade física (idoso AF), idoso risco de quedas (idoso RQ) e adulto.

\begin{tabular}{ccccc}
\hline Grupo & Desvio para a direita & Desvio para a esquerda & Alvo & $\mathrm{N}$ \\
\hline Idoso AF & $56,66 \pm 28,95$ & $40,37 \pm 29,15$ & $2,96 \pm 4,65$ & 27 \\
Idoso RQ & $57,50 \pm 38,87$ & $40,00 \pm 38,37$ & $2,50 \pm 4,52$ & 12 \\
Adulto & $45,18 \pm 26,51$ & $46,66 \pm 26,31$ & $8,14 \pm 9,21$ & 27 \\
\hline
\end{tabular}




\subsection{Efeito do grupo e da variabilidade da direção na trajetória}

Para a análise da trajetória durante a tarefa foi aplicada o DFA (detrended flutuation analysis) e o Random walk obtendo as respectivas variáveis (expoente do DFA, dimensão fractal do DFA, tempo crítico da análise do random walk, dimensão do componente curto e longo da análise do random walk, coeficiente de Hurst do componente curto e longo da análise do random walk) que foram usadas para a análise.

Foi usado análise de variância (ANOVA) de dois fatores para verificar o efeito das variáveis independentes (expoente do DFA; dimensão fractal do DFA; tempo crítico da análise do random walk, Tc; dimensão do componente curto da análise do random walk, DST; dimensão do componente longo da análise do random walk, DLT; coeficiente de Hurst do componente curto da análise do random walk, HST; coeficiente de Hurst do componente longo da análise do random walk, HLT) nas variáveis dependentes grupo (idoso praticante de atividade física, idoso com risco de quedas, adulto) e direção (deslocamento médio- lateral e deslocamento ântero- posterior). A variável dependente chamada de direção foi calculada com base em cada uma das dez tentativas de deslocamento de olhos fechados de cada sujeito.

Foi usada a ANOVA de dois fatores para verificar o efeito dos fatores grupo e direção no expoente do DFA. Os resultados médios e os desvios-padrão do expoente estão na TABELA 21. O grupo $\left(\mathrm{F}_{(2,652)}=48,9\right.$, $\mathrm{p} \leq 0,00001)$ e a direção $\left(\mathrm{F}_{(1,652)}=444,5, \mathrm{p} \leq 0,00001\right)$ afetaram o resultado do expoente. $O$ teste post hoc Tukey HSD indicou maior expoente nos grupos idoso atividade física e idoso risco de quedas e na direção ânteroposterior $(\mathrm{p} \leq 0,0001)$.

TABELA 21: Valores médios e desvio padrão do expoente do DFA nas direções médio-lateral e ânteroposterior para grupos: idoso atividade física (idoso AF), idoso risco de quedas (idoso RQ) e adulto.

\begin{tabular}{cccc}
\hline \multirow{4}{*}{ Grupo } & \multicolumn{2}{c}{ Expoente do DFA } \\
& Médio-lateral & Ântero-posterior & $\mathrm{N}$ \\
\hline Idoso AF & $0,36 \pm 0,13$ & $0,60 \pm 0,22^{*}$ & 268 \\
Idoso RQ & $0,35 \pm 0,12$ & $0,59 \pm 0,20^{*}$ & 118 \\
Adulto & $0,28 \pm 0,13$ & $0,46 \pm 0,23$ & 269 \\
\hline
\end{tabular}

* Significante em $\mathrm{p}<0,05$.

Foi usada a ANOVA de dois fatores para verificar o efeito dos fatores grupo e direção na dimensão fractal do DFA. Os resultados médios e os desvios-padrão da dimensão fractal estão na TABELA 22. O grupo $\left(F_{(2,652)}=48,9, p \leq 0,00001\right.$ e a direção $\left(F_{(1,652)}=444,5, p \leq 0,00001\right)$ afetaram o resultado da dimensão. $O$ teste post hoc Tukey HSD indicou maior dimensão no grupo adulto e na direção médio-lateral ( $\mathrm{p}=0,00002)$. 
TABELA 22: Valores médios e desvio padrão da dimensão fractal do DFA nas direções médio-lateral e ântero-posterior para grupos: idoso atividade física (idoso $\mathrm{AF}$ ), idoso risco de quedas (idoso RQ) e adulto.

\begin{tabular}{cccc}
\hline \multirow{2}{*}{ Grupo } & \multicolumn{2}{c}{ Dimensão fractal } & \\
& Médio-lateral & Ântero-posterior & $\mathrm{N}$ \\
\hline Idoso AF & $2,63 \pm 0,13$ & $2,39 \pm 0,22$ & 268 \\
Idoso RQ & $2,64 \pm 0,12$ & $2,40 \pm 0,20$ & 118 \\
Adulto & $2,71 \pm 0,13^{*}$ & $2,53 \pm 0,23$ & 269 \\
\hline
\end{tabular}

* Significante em $\mathrm{p}<0,05$.

Foi usada a ANOVA de dois fatores para verificar o efeito dos fatores grupo e direção no tempo crítico $(\mathrm{Tc})$. Os resultados médios e os desvios-padrão do tempo crítico estão na TABELA 23. O grupo $\left(F_{(2,652)}=32,3, p \leq 0,00001\right)$ e a direção $\left(F_{(1,652)}=475,7, p \leq 0,00001\right)$ afetaram o Tc. $O$ teste post hoc Tukey HSD indicou maior Tc ocorreu no grupo idoso risco de quedas e na direção ântero-posterior ( $\mathrm{p}=0,00002)$.

TABELA 23: Valores médios e desvio padrão do tempo crítico da análise do random walk nas direções médio-lateral e ântero-posterior para grupos: idoso atividade física (idoso AF), idoso risco de quedas (idoso RQ) e adulto.

\begin{tabular}{cccc}
\hline & \multicolumn{2}{c}{ Tempo crítico (s) } & \\
Grupo & Médio-lateral & Ântero-posterior & $\mathrm{N}$ \\
\hline Idoso AF & $0,07 \pm 0,01$ & $0,09 \pm 0,01$ & 268 \\
Idoso RQ & $0,08 \pm 0,02$ & $0,10 \pm 0,03^{*}$ & 118 \\
Adulto & $0,06 \pm 0,01$ & $0,09 \pm 0,01$ & 269 \\
\hline
\end{tabular}

* Significante em $\mathrm{p}<0,05$.

Foi usada a ANOVA de dois fatores para verificar o efeito dos fatores grupo e direção na dimensão do DST e DHT da análise do random walk. Os resultados médios e os desvios-padrão do DST e DLT estão na TABELA 24. O grupo $\left(\mathrm{F}_{(2,652)}=131,5, \mathrm{p} \leq 0,00001\right)$ e a direção $\left(\mathrm{F}_{(1,652)}=133,2, \mathrm{p} \leq 0,00001\right)$ afetaram o resultado do DST. O teste post hoc Tukey HSD indicou maior DST no grupo adulto e na direção médio-lateral ( $\mathrm{p} \leq 0,00001)$. O grupo $\left(\mathrm{F}_{(2,652)}=12,07, \mathrm{p} \leq 0,00001\right)$ e a direção $\left(\mathrm{F}_{(1,652)}=6,56, \mathrm{p}=0,01\right)$ afetaram o resultado do DLT. O teste post hoc Tukey HSD indicou maior DLT no grupo adulto e na direção ântero-posterior ( $\mathrm{p}=0,02)$. 
TABELA 24: Valores médios e desvio padrão da dimensão do componente curto e longo da análise do random walk nas direções médio-lateral (ML) e ântero-posterior (AP) para grupos: idoso atividade física (idoso AF), idoso risco de quedas (idoso RQ) e adulto.

\begin{tabular}{cccccc}
\hline & \multicolumn{2}{c}{ Dimensão do componente curto } & \multicolumn{3}{c}{ Dimensão do componente longo } \\
Grupo & ML & AP & ML & AP & n \\
\hline Idoso AF & $0,10 \pm 0,10$ & $0,08 \pm 0,12$ & $0,0003 \pm 0,0004$ & $0,0004 \pm 0,0012$ & 268 \\
Idoso RQ & $0,06 \pm 0,06$ & $0,06 \pm 0,06$ & $0,0001 \pm 0,0004$ & $0,0002 \pm 0,0005$ & 118 \\
Adulto & $0,30 \pm 0,20^{*}$ & $0,18 \pm 0,12$ & $0,0004 \pm 0,0007$ & $0,0006 \pm 0,0009^{*}$ & 269 \\
\hline
\end{tabular}

Foi usada a ANOVA de dois fatores para verificar o efeito dos fatores grupo e direção no coeficiente de Hurst do componente curto (HST) e longo (HLT) da análise do random walk. Os resultados médios e os desvios-padrão do HST e HLT estão na TABELA 25. O grupo $\left(\mathrm{F}_{(2,652)}=29,3, \mathrm{p} \leq 0,00001\right)$ e a direção $\left(F_{(1,652)}=605,4, p \leq 0,00001\right)$ afetaram o HST. $O$ teste post hoc Tukey HSD indicou maior HST no grupo idoso risco de queda e na direção médio-lateral $(\mathrm{p} \leq 0,00001)$. $\mathrm{O}$ grupo $\left(\mathrm{F}_{(2,652)}=30,8, \mathrm{p} \leq 0,00001\right)$ e a direção $\left(F_{(1,652)}=178,2, p \leq 0,00001\right)$ afetaram o HLT. O teste post hoc Tukey HSD indicou maior HLT nos grupos idoso atividade física e idoso risco de queda e na direção médio-lateral ( $\mathrm{p} \leq 0,00001)$.

TABELA 25: Valores médios e desvio padrão do coeficiente de Hurst do componente curto e longo da análi-

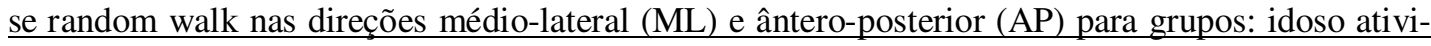
dade física (idoso AF), idoso risco de quedas (idoso RQ) e adulto.

\begin{tabular}{cccccc}
\hline \multicolumn{5}{c}{ Coeficiente de Hurst do componente } & \multicolumn{3}{c}{ Coeficiente de Hurst do componente } \\
curto & AP & ML & AP & longo \\
\hline Grupo & ML & $0,52 \pm 0,10$ & $0,024 \pm 0,021^{*}$ & $0,0074 \pm 0,018$ & 268 \\
\hline Idoso AF & $0,61 \pm 0,07$ & $0,52 \pm 0,08$ & $0,021 \pm 0,024^{*}$ & $0,0053 \pm 0,020$ & 118 \\
Idoso RQ & $0,64 \pm 0,07^{*}$ & $0,46 \pm 0,11$ & $0,010 \pm 0,019$ & $0,0007 \pm 0,014$ & 269 \\
Adulto & $0,58 \pm 0,11$ & & \\
\hline
\end{tabular}

* Significante em $\mathrm{p}<0,05$.

\subsection{Efeito dos testes de risco de quedas na variabilidade da direção da trajetória}

A associação da análise da trajetória da tarefa com os testes que indicam os fatores de risco de quedas acidentais foi feita pelo método de regressão múltipla pela média dos valores dos testes Berg e Tinetti. As variáveis analisadas são: expoente do DFA e dimensão fractal; DST e DLT; HST e HLT.

Para o escore do teste Berg, a regressão múltipla entre os índices gerais de expoente do DFA e dimensão total fractal do DFA nas direções ântero- posterior (AP) e médio-lateral (ML) mostrou que o coeficiente 


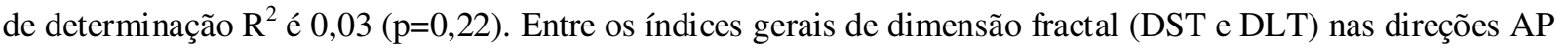
e ML o coeficiente de dterminação $\mathrm{R}^{2}$ é $-0,03$ ( $\left.\mathrm{p}=0,18\right)$. Entre os índices gerais do coeficiente de Hurst (HST e HLT) nas direções AP e ML o coeficiente de determinação $R^{2}$ é $-0,03$ ( $\left.p=0,75\right)$.

Para o escore do teste Tinetti, a regressão múltipla entre os índices gerais do expoente do DFA e a dimensão fractal do DFA nas direções AP e ML mostrou que o coeficiente de determinação $R^{2}$ é 0,003 $(\mathrm{p}=0,38)$. Entre os índices gerais de dimensão fractal (DST e DLT) nas direções AP e ML o coeficiente de determinação $R^{2}$ é $-0,01(p=0,29)$. Entre os índices gerais do coeficiente de Hurst (HST e HLT) nas direções AP e ML coeficiente de determinação $R^{2}$ é $-0,019$ ( $\left.p=0,26\right)$.

\section{DISCUSSÃO}

Para entender a relação entre o risco de quedas acidentais nos idosos, a orientação espacial e o controle postural desenvolvemos este estudo. Comparamos a orientação espacial entre adultos, idosos fisicamente ativos e idosos com fatores de risco de quedas (Gama et al., 2008; Hartikainen et al., 2007; Kelly et al., 2003; Coutinho et al., 2002). O controle postural resulta da integração dos sistemas neuromuscular e sensorial. A integração e coordenação das informações sensoriais dos sistemas somatossenssorial, visual e vestibular (Cook \& Woolacott, 2003) contribuem para a estabilização do corpo em situações instabilidade (Mergner et al., 1994) como na locomoção (Deshpande et al., 2007). A locomoção é uma tarefa automatizada (Hausdorff et al., 2005), controlada no nível do tronco encefálico, porém, para realizá-la de olhos fechados com sucesso, o indivíduo depende da memória (Vuillerme et al., 2002). O controle da locomoção requer a representação dinâmica da relação entre corpo e espaço (Berthoz, 1999). A tendência de não andar em linha reta na ausência da informação visual é chamada de veering (Boyadjian et al., 2001). Quando o indivíduo não consegue construir um referencial do ambiente o risco de não manter o controle postural aumenta, o que pode ocasionar o maior risco de quedas (Hausdorff et al., 2007).

O primeiro objetivo específico desta dissertação de mestrado é estudar a relação da orientação espacial e o controle postural de idosos. Para atingir este objetivo, analisamos o efeito do grupo e de alguns fatores de risco de quedas nos escores dos testes Berg e Tinetti e no teste de orientação espacial.

Os desempenhos nos testes Berg e Tinetti foram usados como indicadores de risco de quedas. O efeito do grupo foi diferente entre os testes aplicados; assim, os adultos apresentaram o maior resultado no teste Berg. Enquanto, os idosos do grupo de risco apresentaram os menores resultados no teste de marcha e no escore do teste Tinetti, maior variabilidade do desvio médio da trajetória e maior dependência da visão na tarefa de orientação espacial.

Os idosos praticantes de atividade física tiveram desempenho semelhante aos adultos nos testes de mobilidade e de orientação espacial o que sugere que a atividade física é fator que ajuda a manter a função física (Huang et al., 2003; Kell et al., 2001; Okuma, 1998; Spirduso, 1995; Carter et al., 2002; Gregg et al., 1998). Por outro lado, os idosos com risco de quedas tiveram desempenho menor nos mesmos testes, o que 
sugere um menor controle postural e uma maior instabilidade no andar (Karamanidis et al., 2008; Kesler et al., 2005), fator que influencia no risco de quedas (Hausdorff, 2007).

Os fatores de risco de quedas afetaram os escores dos testes Berg e Tinetti e de orientação espacial; a lateralidade não afetou nenhum escore. Esses escores são piores quando existe histórico de quedas, problema de visão, labirintite ou a ingestão de medicamentos (Hartikainen et al., 2007; Kelly et al., 2003; Coutinho et al., 2002; Gama et al., 2008). O problema de visão e a ingestão diária de medicamentos também pioram o desempenho no teste de orientação espacial. Ter sofrido queda anteriormente e ingerir mais de 3 medicamentos diários são fatores associados ao risco de quedas na literatura (Gama et al., 2008) e os resultados deste estudo comprovam esse comportamento de risco, ou seja, os idosos com antecedente de queda apresentam maior dificuldade para estabilização do tronco (Spring et al., 2006) e os idosos que fazem uso diário de remédios têm maior chance de sofrer queda do que aqueles que não tomam (Kelly et al., 2003; Coutinho et al., 2002; Gama et al., 2008). Ter problemas de visão pode estar associado à maior dependência da visão para referência espacial (Mergner et al., 1994; O'Connor et al., 2009), o que sugere que os idosos são mais dependentes da visão para a manutenção do controle postural do que os adultos (Harwood, 2001) e que, em situações de restrição da informação visual há um grande decréscimo na estabilidade postural (Kesler et al., 2005), porque ambientes pouco iluminados (Huang et al., 2003) e problemas na visão (Harwood, 2001) aumentam o risco de quedas nos idosos. O efeito da labirintite está associado à influência do sistema vestibular no controle postural (Deshpande et al., 2007). A não influência da lateralidade no desempenho do teste de orientação espacial sugere que o comportamento do veering não está associado com a preferência lateral (Mohr et al., 2003), ao contrário do que sugeriu Boyadjian et al. (1999) e Day et al. (1997).

O segundo objetivo específico desta dissertação é comparar a orientação espacial entre adultos e idosos. Para este objetivo, analisamos o veering e o efeito do grupo e do risco de quedas no teste de orientação espacial. Para o veering, calculamos os erros absoluto, variável e constante, o ângulo do desvio e a porcentagem da direção do desvio do alvo. O grupo afetou o erro absoluto e variável, mas não afetou o erro constante. O grupo idoso RQ apresentou o maior resultado no erro absoluto e variável. Thomson (1983) mostra que, em distâncias maiores que $12 \mathrm{~m}$ com a visão completamente excluída, $5 \mathrm{~s}$ depois da visualização do alvo, o erro variável aumenta consideravelmente, ou seja, o desvio do alvo. Assim, os idosos suscetíveis às quedas têm maior dificuldade de manter internalizada a informação sobre o caminho quando a distância percorrida sem visão é maior de $12 \mathrm{~m}$ (Thomson, 1983). O grupo não afetou o ângulo médio do desvio, mas afetou a variabilidade. Os idosos com risco de quedas sofreram maior veering. Enquanto que os idosos que realizam atividade física e os adultos apresentaram menor veering. Isso sugere que a atividade física influencia positivamente a manutenção da memória espacial no processo do envelhecimento.

Em relação à consistência da direção do desvio do alvo, não houve diferença entre grupos. Todos os grupos tiveram maior desvio para a direita, sem mostrar comportamento homotrópico (Boyadjian et al., 1999)

A análise do DFA (detrended flutuation analysis) mostra flutuações em uma série temporal por meio da 
correlação de longa duração nas oscilações dessa série (Stergiou, 2004). Esta análise mostrou que o controle da trajetória nas direções de movimento apresenta comportamentos distintos. A primeira diferença que se destaca é dos valores do exponte do DFA, que indica se o sistema opera com ou sem feedback (Peng et al, 1994). Se o expoente está entre 0,5 e 1 , o sistema é persistente; e caso seja menor que 0,5 , o sistema é antipersistente. O expoente do DFA dos grupos é menor que 0,5 na direção médio-lateral. Desta forma, qualquer correção da trajetória planejada na direção médio-lateral é anti-persistente, caracterizando um sistema aberto (Collins et al, 1992). Na direção ântero-posterior, o expoente dos dois grupos de idosos foi maior que 0,5. Assim, o mecanismo de controle de orientação espacial na direção ântero-posterior dos idosos é persistente, ou seja, existe aproveitamento das informações sensoriais e da trajetória virtual (Philbeck et al., 2001; Thomson, 1983) para a correção da oscilação postural na direção AP (Mochizuki, 2002). As alterações do expoente do DFA com a idade sugerem outros tipos de mudanças na marcha do idoso, além das consagradas como a diminuição da velocidade da marcha, do comprimento do passo, do aumento do tempo de duplo apoio e da variabilidade do passo (Cook, Woollacott, 2003; Warren, Wertheim, 1990; Brooks, 1986; Macardle, Katch, Katch, 1998; Shephard, 1997; Spirduso, 1995; Weinck, 1991).

A dimensão fractal indica o nível de complexidade do sistema. A dimensão fractal do DFA foi maior nos adultos e na direção médio-lateral. Isso sugere que o sistema que controla a locomoção dos adultos é mais complexa que dos idosos. Da mesma forma, sugere-se que o controla da locomoção na direção AP e ML tem níveis diferentes de complexidade.

A análise do random walk é resultado de uma combinação de mecanismos determinísticos e estocásticos (Collins et al, 1992). A partir da análise do random walk é possível obter o tempo crítico, ou seja, o valor do $\Delta \mathrm{t}$ em que o deslocamento passa do comportamento anti-persistente (sistema aberto) para um comportamento persistente (sistema fechado). O maior tempo crítico ocorreu no grupo idoso com risco de quedas e na direção ântero-posterior. Esse resultado sugere que o idoso que tem risco de quedas precisa de mais tempo para reconhecer as mudanças da trajetória da marcha e possa propor uma alteração na orientação. Os idosos praticantes de atividade física e os adultos tiveram um desempenho similar no tempo de correção da trajetória o que pode ser um indicador que a atividade física pode manter por mais tempo o comportamento do processamento das informações no SNC.

Outro resultado da análise do random walk são os coeficientes de difusão e de Hurst. Neste estudo, o uso do Random Walk permitiu calcular esses dois parâmetros na fase anti-persistente (componente curto) e persistente (componente longo). A dimensão do componente curto (DST) é caracterizada por ser uma fase de maior atividade estocástica e, portanto, possuir o maior coeficiente de difusão. O maior resultado do DST foi nos adulto e na direção médio-lateral. A fase do componente longo (DLT) é menos estocástica e possui o menor coeficiente de difusão. O maior resultado do DLT no grupo adulto e na direção ântero-posterior. Logo, na fase com o uso do feedback, os adultos apresentam maior complexidade no sistema que controla a locomoção. Como anteriormente foi mencionado na analise do DFA, novamente encontramos evidencias que 
o controle da locomoção dos adultos pode energizar os filhos. O coeficiente $\mathrm{H}$ pode variar de 0 a 1 . Se $\mathrm{H}$ for maior que 0,5 , o processo estocástico é correlacionado positivamente, ou seja, o aumento ou a diminuição da tendência no passado implica no aumento ou na diminuição da tendência no futuro, o que caracteriza um comportamento persistente. Se $\mathrm{H}$ for menor que 0,5 , o processo estocástico é correlacionado negativamente, ou seja, o passado e o futuro são incrementos negativamente correlacionados, que caracteriza um comportamento anti- persistente. Tanto na fase curta quanto longa, a direção ML apresentou maior coeficiente de Hurst e o grupo de adultos mostrou o menor coeficiente. O'Connor et al. (2009) verificaram que a visão é responsável pelo controle da oscilação do tronco na direção ML na locomoção. Logo, a dependência da visão no controle da oscilação do tronco dos idosos pode estar associada ao comportamento anti-persistente. A maior aceleração do tronco na direção ML pode aumentar o risco de quedas (Marigold et al., 2008).

A dimensão fractal do sistema foi maior nos adultos; enquanto que a dimensão fractal dos componentes curto e longo foi diferente entre as direções do movimento. A dimensão fractal do componente curto foi maior na direção ML, e do componente longo, na direção AP. A diferença de dimensão na fase anti-persistente e persistente reforça a sugestão que há independência o controle da locomoção com os olhos fechados nas direcoes AP e ML.

Como tronco é o segmento do corpo que possui a maior massa corporal (Winter, 1990), sua oscilação influencia a dinâmica da estabilidade do corpo durante a locomoção. Os idosos apresentam maior intensidade dos coeficientes do DFA e do Random walk, o que sugere uma maior atividade estocástica e, portanto, uma menor estabilidade dinâmica na marcha em relação aos adultos (Gu Kang et al., 2009). O maior tempo para correção da trajetória e a maior oscilação corporal pode ser resultado das características do envelhecimento como a diminuição da condução ou da velocidade dos impulsos nervosos e da capacidade ou velocidade de interpretação das informações recebidas dos sistemas sensoriais e, o aumento do tempo das respostas reflexas (Hausdorff, 2007).

A associação da análise da trajetória com os testes que indicam os fatores de risco de quedas acidentais foi feita por meio de modelo de regressão linear múltipla. Relacionamos o desempenho nos teste Berg e Tinetti com os resultados da análise do DFA e do random walk. Não encontramos relação linear do teste Berg ou Tinetti com o expoente do DFA e dimensão fractal do DFA, com a dimensão fractal curta e longa ou com os coeficientes de Hurst curto ou longo, em ambas as direções. Logo, não existe relação linear do risco de quedas, avaliado por meio dos testes Berg e Tinetti, com a dinâmica da locomoção no teste de orientação espacial.

O objetivo principal desta dissertação de mestrado é estudar o risco de quedas durante a locomoção sem informação visual. Na ausência da visão, a locomoção depende da disponibilidade da informação acurada sobre a distância e a direção do alvo; da habilidade de internalizar informações sobre o caminho; da habilidade de planejar e monitorar a execução do passo; da habilidade de manter atualizada a posição do corpo com a representação internalizada da base (Thomson, 1983), a diminuição do domínio dessas capacidades pode influenciar no risco de quedas. 
Nossos resultados mostraram que os idosos com risco de quedas possuem a maior variabilidade do desvio, o maior erro absoluto e variável e, portanto, o maior veering. Em relação às análises das séries temporais, esse mesmo grupo apresentou os maiores valores do coeficiente do DFA na direção AP, do coeficiente de Hurst na direção ML e maior tempo de correção da trajetória. O grupo idoso praticante de atividade física apresentou maiores coeficientes do DFA na direção AP e do coeficiente de Hurst apenas na direção ML. Esses resultados sugerem que o tempo que os idosos ficam sem visão influencia a locomoção. Thomson (1983) sugeriu o limiar de tempo de $8 \mathrm{~s}$ para o uso da memória de curto prazo, e ao percorrer a distância de 15m, em um tempo maior ao limiar, os idosos passaram a oscilar mais na direção ML, diminuindo assim, as informações internalizadas sobre o caminho e a habilidade de manter atualizada a posição do corpo com a representação internalizada da base. Os adultos parecem manter a informação internalizada sobre o caminho de forma mais genérica permitindo que a atividade seja controlada em distâncias maiores, sendo flexíveis para permitir que a atividade motora seja reorganizada sem a necessidade de consultar a visão (Thomson, 1983).

A hipótese do estudo indica que o veering não sofreria efeito do grupo estudado. Os idosos são mais dependentes da visão para estabilizar o corpo na direção médio-lateral durante a locomoção. Os idosos com risco de quedas apresentam maior veering e, portanto, tem menor controle da orientação espacial durante a locomoção sem visão, fator que pode aumentar ainda mais o risco de quedas. Por outro lado, os idosos praticantes de atividade física e os adultos apresentam comportamentos parecidos quanto ao veering, o que sugere que a atividade física pode retardar o processo do envelhecimento quanto à estabilidade dinâmica e à memória espacial durante a locomoção sem visão e assim, diminuir o risco de quedas. Como conseqüência, observamos que a hipótese inicial foi refutada. Assim, o veering sofreu efeito do grupo.

\section{CONCLUSÃo}

O objetivo desta dissertação de mestrado é estudar o risco de quedas durante a locomoção sem informação visual. Os resultados sugerem que o controle da oscilação do tronco para frente ou para o lado durante locomoção segue estratégias diferentes e parecem agir de forma independente. O controle da oscilação na direção ML define o desvio da trajetória e tem comportamento anti-persistente, ou seja, comporta-se como um sistema aberto. $\mathrm{O}$ controle da oscilação na direção AP tem um comportamento persistente, ou seja, o sistema é fechado e usa as informações dos sistemas sensoriais para comparar com trajetória virtual construída mentalmente a fim de consertar a trajetória.

Em relação a hipótese inicial, verificamos que o veering é maior nos idosos que apresentam fatores de risco de quedas. 


\section{REFERÊNCIAS BIBLIOGRÁFICAS}

Beauchet O; Annweiler C; Allali G; Berrut G; Herrmann F. R; Dubost V. Recurrent falls and dual task- related decrease in walking speed: Is there a relationship? Jounal of American Geriatric Society, 2008, 56: 1265-1269.

Berg W.P; Alessio H.M; mills E.M; Tong C. Circunstances and consequences of falls in independent community-dwelling older. Age and ageing , 1997, 26 (4):261-8.

Berthoz A. Viaud-Delmon I. Multisensory integration in spatial orientation. Curr Op Neurobiol, 1999 (9): 708-712.

Bertin R. J. V; Berthoz A. Visuo-vestibular interaction in the reconstruction of travelled trajectories. Exp Brain Res, 2004, 154: 11-21.

Bigongiari A; Cosme R. G. Mochizuki L. Postura na infância e adolescência: características biomecânicas e do comportamento motor. In Rose D. Esporte e atividade física na infância e adolescência, uma abordagem multidisciplinar. Porto Alegre, ed Artmed, 2009.

Bonnard M; Pailhous J; Danion F. Adaptation of neuromuscular synergies during intentional constraints of space- time relashionships in human gait. Journal of Motor Behavior, 2000, 2(32): 200-208.

Boyadjian A, Marin L, Danion F Veering in human locomotion: the role of the effectors. Neurosc lett, 1999, 265: 21-24.

Brooks V. B. The neural basis of motor control. Oxford University, 1986.

Bruijn SM; Dieen JH; Meijer OG; Beek PJ. Is slow walking more stable? J Biomech, 2009, 42: 1506-1512.

Campbell A.J; Borrie M. J; Spears G.F; Jackson S.L; Brown J.S; Fitzgerald J.L. Circunstances and consequences of falls experience 70 years and over during a prospective study. Age Ageing, 1990, 19:136-41.

Carter ND; Khan KM; Mckay HA; Waterman C; Heinonen A. Community-based exercise program reduces 75 year old women with osteoporosis: Randomized controlled trial. Can Med Association J 2002, 16.

Castro E. M; Paula A. I; Tavares C. P; Moraes R. Orientação espacial em adultos com deficiência visual: efeitos de um treinamento de navegação. Psicologia: reflexão e crítica, 2004, 17 (2): 199-210.

Choy N. L., Brauer S., Nitz J. Changes in postural stability in women age 20 to 80 years. J Geron: Medical Sciences, 2003, 58a(6): 525-530.

Christopher S; Kallie, Paul R; Schrater; Gordon E. Legge. Variability in stepping direction explains the veering behavior on blind walkers. J Exp Psy: Human Percept Perform 2007, 33(1): 183-200.

Collins J. J; De Luca C. J. Open-loop and closed-loop control of posture: a random-walk analysis of center-ofpressure trajectories. Experimental Brain Research, 1992, 307-318.

Cook A. S; Woolacott M. H. Controle motor-teorias e aplicações práticas. Ed Manole; 2 edição, 2003.

Cosme, RG, Mochizuki, L, Serrão, JC, Amadio, AC. Efeito da altura da base de apoio nos ajustes posturais em idosos. Anais do II Congresso Brasileiro de Comportamento Motor, 2004.

Cotton R. Exercise for older adults. ACE's guide for fitness professionals. Champaign, Human Kinects, 1998. 
Coutinho E. S. F; Silva, S. D. Uso de medicamentos como fator de risco para fratura grave decorrente de queda em idosos. Cad. Saude Publica, 2002, 18 (5): 1359-1366.

Cumming RG. Epidemiology of medication- related falls and fractures in the elderly. Drugs \& Aging, 1998, 12(1): 43:53.

Cummings S.R; Nevitt M.C; Browner W.S; Stone K; Fox K.M; Ensrud K.E et al. Risk factors for hip facture in white women. New England Journal of medicine 1995; 332(12):767-73.

Danion F; Boyadjian A; Marin L. Control of locomotion in expert gymnasts in the absence of vision. Journal of Sports Sciences, 2000, 18: 809-814.

Danion F; Varraine E; Bonnard M; Pailhous J. Stride variability in human gait: the effect of stride frequency and stride length. Gait and Posture, 2003, 18: 69-77.

Day H. D; Vickie J. G. Veering in women: inconsistency of forward and backward progression. Perceptual and Motor skills, 1997, 85: 587-596.

Demura S; Uchiyama M. Proper assessment of falling risk in the elderly by a physical mobility test with an obstacle. Tohoku J. Exp. Med, 2007, 212: 13-20.

Deshpande N. Plata A. E. Postural responses and spatial orientation to neck proprioceptive and vestibular inputs during locomotion in young and older adults. Exp Brain Res, 2005, 167: 468-474.

Deshpande N. Plata A. E. Visual- vestibular interaction during goal directed locomotion: effects of aging and blurring vision. Exp Brain Res, 2007, 176: 43-53.

Egerton T; Brauer S. G. The immediate effect of physical activity on standing balance in healthy and balanceimpaired older people. Australasian Journal of Ageing, 2009, 28(2): 93-96.

Gama Z. A. S; Gomez- Conesa A. Factores de riesgo de caídas em ancianos: revision sistemática. Ver Saúde Publica, 2008, 42(5): 946-956.

Gillespie L.D; Gillespie W.J; Robertson M.C; Lamb S.E; Cumming R.G; Rowe B.H. Interventions for preventing falls in elderly people. The Cochrane Library, 2, 2005.

Gregg EW; Cauley JA; Seeley DG; Ensrud KE; Bauer DC. Physical activity and osteoporotic fractures risk in older women. Ann Intern Med 1998, 129: 81-88.

Gu Kang H; Dingwell J. B. Dynamic stability of superior vs inferior segments during walking in young and older adults. Gait \& Posture, 2009, 30: 260-263.

Guth $\mathrm{D}$; LaDuke R. The veering tendency of blind pedestrians: an analysis of the problem and literature review. Journal of visual impairment \& Blindness, 1994, 88: 391-400.

Hartikainen S; Lonnroos E; Louhivuori K. Medical as a risk factor for falls: critical systematic review. Journal of Gerontology: Medical Sciences, 2007, 62A(10): 1172-1181.

Harwood R. H. Visual problems and falls. Age and Ageing , 2001, 30(S4): 13-18.

Hausdorff J.M. Gait dynamics, fractals and falls: finding meaning in the stride- to- stride fluctuations of human walking. Hum Mov Sci, 2007, 26 (4): 555-589. 
Hausdorff J.M., Yogev G., Springer S, Simon E.S, Giladi N. Walking is more like catching than tapping: gait in the elderly as a complex cognitive task. Exp Brain Res, 2005, 164: 541-548.

Hausdorff JM; Ashkenazy Y; Peng CK; Ivanov PC; Stanley HE; Goldberger AL. When human walking becomes random walking: fractal analysis and modeling of gait rhythm fluctuations. Physica A, 2001, 302: 138-147.

Haywood K. M., Getchell N. Desenvolvimento motor ao longo da vida. Ed Artmed, 3 edição, 2004.

Horak FB; Hlavacka F. Somatosensory loss increases vestibulospinal sensitivity. J Neurophysiol, 2001, 86: 575-585.

Huang HC; Gau ML; Lin WCL; Kernohan G. Assessing risk of falling in older adults. Public Health Nursing, 2003, 5(20): 399-411.

IBGE 2006-acesso em 09/06: http://www.ibge.gov.br/home/estatistica/populacao/projecao_da_populacao/ piramide.

IBGE2009-acesso06/09:

HTTP://www.ibge.gov.br/home/estatistica/populacao/projecao_da_populacao/2008/piramide

IPAQ- questionário e classificação- acesso em 08/2009: www.celafiscs.institucional.ws/65/questionarios.html

Kallie C S; Schrater P R; Legge G E. Variability in stepping direction explains the veering behavior of blind walkers. J. Exp Psychol Hum Percept Perform, 2007, 33 (1): 183-200.

Karamanidis K; Arampatzis A; Mademli L. Age- related deficit in dynamic stability control after forward falls is affected by muscle strength and tendon stiffness. J Electromyograph Kines, 2008, 18:980-989.

Kausler D. H. Learning and memory in normal anging. Ed. Academic Press, 1994.

Kell RT; Bell G; Quinney A. Muscoloskeletal Fitness, Health Outcomes and Quality of life. Sports Med, 2001, 31(12): 863-873.

Kelly K. D; Pickett W; Yiannakoulias N; Rowe B. H; Schopflocher D. P; Sverson L; Voaklander D. C. Medication use and falls in community-dwelling older persons. Age Anging 32(5): 503-509, 2003.

Kesler A, Leibovich G, Herman T, Gruendlinger L, Giladi N, Hausdorf JM. Shedding light on walking in the dark: The effects of reduced lighting on the gait of older adults with a Higher-Level Gait Disorder and Controls. Journal of NeuroEngineering and Rehabilitation 2005, 28:2-27

Lowrey C R; Watson A; Vallis L A. Age- related changes in avoidance strategies when negotiating single and multiple obstacles. Exp Brain Res, 2007, 182: 289-299.

Marigold DS, Patla AE. Age-related changes in gait for multi-surface terrain. Gait Posture, 2008, 27: 689-696.

Matsudo SMM. Avaliação do idoso, física e funcional. Londrina, Midiograf, 2000.

Maurer C., Mergner T. Bolha B., Hlavacka F. Vestibular, visual, and somatosensory contributions to human control of upright stance. Neuroscience Letters, 2000, 281: 99-102.

Mcardle DW; Katch I. F.; Katch L. V. Fisiologia do exercício. Energia, Nutrição e Desempenho Humano. Editora Guanabara Koogan, 1998. 
Mergner T; Hlavacka F. Multisensory control of posture. Ed. Plenum Publishing Corporation, 1994.

Millar S. Veering re- visited: noise and posture cues in walking without sight. Perception, 1999, 765-780.

Mochizuki L. Análise biomecânica da postura humana: estudos sobre o controle do equilíbrio. Tese Doutorado, Escola de Educação Física e Eporte, USP, São Paulo, 2002.

Mochizuki, L Amadio, AC A aplicação da análise dos componentes principais para o estudo do controle postural. Revista Brasileira de Educação Física e Esporte, 2007, (21): 301- 305.

Mochizuki, L; Cosme, RG, Amadio, AC. Coordenação motora e controle postural por meio de análise multivariada. Motriz, 2006, (12):1-9.

Mohr C., Brugger P., Bracha H. S., Landis T., Viaud-Delmon I. Human side preferences in three different whole-body movement tasks. Behav Brain Research, 2003, 151: 321-326.

O'Connor S. M; Kuo A. D. Direction dependent control of balance during walking and standing. Journal of Neurophysiology, 2009, 102: 1411- 1419.

Okuma S. S. Idoso e Atividade Física; Fundamentos e Pesquisa. Campinas, Papirus, 1998.

OMS: acesso em 08/2009: http://portal.prefeitura.sp.gov.br/secretarias/participacao_parceria/coordenadorias/idosos/artigo/0011

Pardini R; Matsudo S; Araújo T; Matsudo V; Andrade E; Braggion G; Andrade D; Oliveira L; Figueira Jr A; Raso V. Validação do questionário internacional de nível de atividade física (IPAQ- versão 6): estudo piloto em adultos jovens brasileiros. Revista Brasileira Ciência e Movimento, 2001, 9(3): 45-51.

Pascal P., Ivanenko Y., Grasso R., Berthoz A. Spatial invariance in anticipatory orienting behaviour during human navigation. Neuroscience Letters, 2002, 339: 243-247.

Patla A. E; Tomescu S. S; Ishac M. G. A. What visual information is used for navigation around obstacles in a cluttered environment? Can. J. Physiol. Pharmacol, 2004, 82: 682-692.

Patla A.E. Some characteristics of EMG patterns during locomotion: implications for locomotor control processes. Jounal of Motor Behavior, 1985, 17: 443-461.

Peng C. K; Havlin S; Goldberger A. L. Quantification of scaling exponents and crossover phenomena in nonstationary heartbeat time series. American Institute of Physlcs, 1995, 5(1): 82-87.

Perrin P; Lestienne F. Mecanismos do equilíbrio humano. França, Organização Andrei, 1998.

Philbeck JW, Klatzky RL, Behrmann M, Loomis JM, Goodridge J. Active Control of locomotion facilitates nonvisual navigation. J Exp Psychol: Hum Percep Performance, 2001, 27(1): 141-153.

Rietdyk S; Rhea C. K. Control of adaptive locomotion: effect of visual obstruction and visual cues in the environment. Exp Brain Res, 2006, 169: 272-278.

Rikli R; Jones J. Development and validation of a function fitness test for community-residing older adults. Journal of Anging and Physical Activity, 1999, 7: 129-161.

Rikli R; Jones J. Function fitness normative scores for community-residing older adults, ages 60-94. Journal of Anging and Physical Activity, 1999, 7: 162-181. 
Rothwell J. Control of human voluntary movement. 2nd ed. London: Chapmann \& Hall, 1994.

Salgado M. A. Velhice: uma nova questão social. São Paulo. SESC, série terceira idade, 1980.

Schoueri JR; Ramos RL; Papaléo MN. Crescimento populacional: aspectos demográficos e sociais. In: Carvalho Filho ET; Papaléo MN. eds. Geriatria: fundamentos, clínica, terapêutica. São Paulo, Atheneu, 1994, 9-29.

Shephard JR. Envelhecimento, atividade física e saúde. Phorte editora Ltda, 1997.

Silva A; Almeida GJM; Cassilhas RC; Cohen M; Peccin MS; Tufik S; Mello MT. Equilíbrio, coordenação e agilidade de idosos submetidos à prática de exercícios físicos resistidos. Rev Bras Med Esporte, 2008, 2(14): 88-93.

Skelton DA; Beyer N. Exercise and injury prevention in older people. Scan J Med Scie Sports, 2003, 13: 7785.

Souza L.; Galante H.; Figueiredo D. Qualidade de vida e bem-estar dos idosos: um estudo exploratório na população portuguesa. Rev. Saúde Pública, 2003, 37(3): 364-71.

Spirduso, W.W. Physical dimensions of aging. Champaign, Human Kinetics, 1995.

Spring S; Giladi N; Peretz C; Yogev G; Simon E. S; Hausdorff J. M. Dual-tasking effects on gait variability: the role of anging, falls, and executive function. Movements Disordes, 2006, 21(7): 950-957.

Stergiou N. Innovative analyses of human movement. Human Kinetics, 2004.

Thomson J. A. Is continuos visual monitoring necessary in visually guided locomotion? Journal of Experimental Psychology, 1983, 9(3): 427- 443.

Tinetti ME. Prevention of falls and fall injuries in elderly persons: a research agenda. Prev Med 1994, 23:75662.

Tinetti M.E; Speechley M; Ginter S.F. Risk factors for falls among elderly persons living in the comunity. New England of Journal of Medicine, 1988, 319 (26): 1701-1707.

Valiquette C. M., Mcnamara T. P., Smith K; Locomotion, incidental learning, and the selection of spacial reference systems. Memory \& Cognition, 2003, 31(3): 479-486.

Vuillerme N, Nougier V, Camicioli R. Veering in human locomotion: modulatory effect of attention. Neuroscie Lett, 2002, 331: 175-178.

Warren R; Werthem A. H. Perception \& Control of self-motion; 1990, Lawrence Erlbaum Associates

Weineck, J. Biologia do esporte. São Paulo. Monole, 1991.

Winter D. A. Biomechanics and Motor Controlo f Human Movement. 2ed, New York: John Wiley \& Sons, Inc, 1990. 


\section{ANEXO 1- QUESTIONÁRIO DE AVALIAÇÃO INICIAL}

Nome:

Data nascimento:

telefones

Peso:

1

1

idade:

altura:

Você já sofreu uma queda no período de 1 ano? Quantas? Como? Fraturas?

Tem problemas de visão? Quais?

Sua pressão é alta ou baixa? Toma remédio? Quais?

Você tem Diabetes? Toma insulina? Qual a dosagem?

Você tem labirintite? Toma medicamentos?

Quantos e quais comprimidos você ingere ao dia?

Você tem algum problema osteo-muscular / cirurgia recente que prejudique seu andar?

Você consegue caminhar de olhos fechados?

Você pratica exercícios físicos? Quais? Quando você iniciou a prática de exercícios físicos?

Caso a resposta seja SIM responda o questionário do IPAQ.

Você é destro ou canhoto? 


\section{ANEXO 2- QUESTIONÁRIO DE AVALIAÇÃO DA CAPACIDADE FUNCIONAL}

Para as seguintes atividades assinale o número $(1,2,3)$ que melhor expressa a sua capacidade de realizar essa atividade, independente de você realizá-la ou não. (1) Realiza sem ajuda e com facilidade; (2) Realiza sem ajuda mas com dificuldade; (3) realiza com ajuda ou depende de outros para realizar

\begin{tabular}{|l|l|l|l|}
\hline \multicolumn{1}{|c|}{ Atividade } & 1 & 2 & 3 \\
\hline Comer e beber & & & \\
\hline Lavar o rosto e as mãos & & & \\
\hline Ir ao banheiro & & & \\
\hline Levantar da cadeira & & & \\
\hline Entrar e sair da cama & & & \\
\hline Movimentar-se dentro de casa & & & \\
\hline Vestir-se & & & \\
\hline Tomar banho & & & \\
\hline Mover-se fora da casa em terreno plano & & & \\
\hline Subir e descer escadas & & & \\
\hline Cuidar dos pés e das unhas & & & \\
\hline Atividades leves de limpeza de casa & & & \\
\hline Preparar o jantar & & & \\
\hline Preparar o café da manhã e o almoço & & & \\
\hline Arrumar a cama & & & \\
\hline Lavar e passar roupa & & & \\
\hline Fazer compras & & & \\
\hline Atividades pesadas de limpeza da casa & & \\
\hline
\end{tabular}

Para as seguintes atividades assinale o número $(1,2,3)$ que melhor expressa a sua capacidade de realizar essa atividade, independente de você realizá-la ou não. (1) faço; (2) faço com dificuldade ou com ajuda; (3) não faço

\begin{tabular}{|l|l|l|}
\hline \multicolumn{1}{|c|}{ Atividade } & $\mathbf{1}$ & $\mathbf{2}$ \\
\hline Tomar conta das suas necessidades pessoais como vestir-se sozinha & & \\
\hline Tomar banho, usar a banheira & & \\
\hline Caminhar fora de casa (1 a 2 quarteirões) & & \\
\hline Fazer atividades domésticas leves como cozinhar, tirar o pó, lavar pratos, varrer ou andar pela casa & & \\
\hline Subir e descer escadas ou marchar & & \\
\hline Fazer compras no supermecado ou no shopping & & \\
\hline Levantar e carregar 5 Kg (como por exemplo um pacote de arroz) & & \\
\hline Caminhar 6 a 7 quarteirões & & \\
\hline Caminhar 12 a 14 quarteirões & & \\
\hline Levantar e carregar 13 Kg (como por exemplo uma mala média a grande) & \\
\hline Fazer atividades domésticas pesadas como aspirar, esfregar pisos & \\
\hline $\begin{array}{l}\text { Fazer atividades vigorosas como andar grandes distâncias, cavucar o jardim, mover objetos pesados, } \\
\text { atividades de dança ou ginástica }\end{array}$ & & \\
\hline
\end{tabular}

Classificação do nível funcional para a escala proposta por Rikli e Jones (1999):

Avançado: realiza 12 itens sem dificuldade

Moderado: realiza 7 a 11 itens sem dificuldade

Baixo: 6 sem dificuldade ou inábil para realizar 3 ou mais AIVDs: carregar 5kg, caminhar 6 a 7 quarteirões, fazer tarefas domésticas. 


\section{ANEXO 3- QUESTIONÁRIO DO NÍVEL DE ATIVIDADE FÍSICA IPAQ}

Nome:

Idade: Sexo: F ( ) M ( ) Você trabalha de forma remunerada: ( ) Sim ( ) Não.

Data: _ _ _ _ _ _

Quantas horas você trabalha por dia: Quantos anos completos você estudou:

De forma geral sua saúde está: ( ) Excelente ( ) Muito boa ( ) Boa ( ) Regular ( )Ruim

Nós estamos interessados em saber que tipos de atividade física as pessoas fazem como parte do seu dia a dia. Este projeto faz parte de um grande estudo que está sendo feito em diferentes países ao redor do mundo. Suas respostas nos ajudarão a entender que tão ativos nós somos em relação à pessoas de outros países. As perguntas estão relacionadas ao tempo que você gasta fazendo atividade física em uma semana ultima semana. As perguntas incluem as atividades que você faz no trabalho, para ir de um lugar a outro, por lazer, por esporte, por exercício ou como parte das suas atividades em casa ou no jardim. Suas respostas são MUITO importantes. Por favor, responda cada questão mesmo que considere que não seja ativo. Obrigado pela sua participação!

Para responder as questões lembre que:

$>$ Atividades físicas VIGOROSAS são aquelas que precisam de um grande esforço físico e que fazem respirar MUITO mais forte que o normal

$>$ Atividades físicas MODERADAS são aquelas que precisam de algum esforço físico e que fazem respirar UM POUCO mais forte que o normal

SEÇÃO 1- ATIVIDADE FÍSICA NO TRABALHO

Esta seção inclui as atividades que você faz no seu serviço, que incluem trabalho remunerado ou voluntário, as atividades na escola ou faculdade e outro tipo de trabalho não remunerado fora da sua casa. NÃO incluir trabalho não remunerado que você faz na sua casa como tarefas domésticas, cuidar do jardim e da casa ou tomar conta da sua família. Estas serão incluídas na seção 3.

1a. Atualmente você trabalha ou faz trabalho voluntário fora de sua casa?

( ) Sim ( ) Não - Caso você responda não Vá para seção 2: Transporte

As próximas questões são em relação a toda a atividade física que você fez na ultima semana como parte do seu trabalho remunerado ou não remunerado. NÃO inclua o transporte para o trabalho. Pense unicamente nas atividades que você faz por pelo menos 10 minutos contínuos:

1b. Em quantos dias de uma semana normal você anda, durante pelo menos 10 minutos contínuos, como parte do seu trabalho?Por favor, NÃO inclua o andar como forma de transporte para ir ou voltar do trabalho.

dias por SEMANA ( ) nenhum - Vá para a secão 2 - Transporte.

1c. Quanto tempo no total você usualmente gasta POR DIA caminhando como parte do seu trabalho? horas minutos

1d. Em quantos dias de uma semana normal você faz atividades moderadas, por pelo menos 10 minutos contínuos, como carregar pesos leves como parte do seu trabalho? dias por SEMANA ( ) nenhum - Vá para a questão 1f

1e. Quanto tempo no total você usualmente gasta POR DIA fazendo atividades moderadas como parte do seu trabalho? horas minutos

1f. Em quantos dias de uma semana normal você gasta fazendo atividades vigorosas, por pelo menos 10 minutos contínuos, como trabalho de construção pesada, carregar grandes pesos, trabalhar com enxada, escavar ou subir escadas como parte do seu trabalho: dias por SEMANA ( ) nenhum - Vá para a questão 2a.

1g. Quanto tempo no total você usualmente gasta POR DIA fazendo atividades físicas vigorosas como parte do seu trabalho? horas minutos

SEÇÃo 2 - ATIVIDADE FÍSICA COMO MEIO DE TRANSPORTE 
Estas questões se referem à forma típica como você se desloca de um lugar para outro, incluindo seu trabalho, escola, cinema, lojas e outros.

2a. O quanto você andou na ultima semana de carro, ônibus, metrô ou trem?

$$
\text { dias por SEMANA ( ) nenhum - Vá para questão 2c }
$$

2b. Quanto tempo no total você usualmente gasta POR DIA andando de carro, ônibus, metrô ou trem? horas minutos

Agora pense somente em relação a caminhar ou pedalar para ir de um lugar a outro na ultima semana.

2c. Em quantos dias da ultima semana você andou de bicicleta por pelo menos 10 minutos contínuos para ir de um lugar para outro? (NÃO inclua o pedalar por lazer ou exercício) dias por SEMANA ( ) Nenhum - Vá para a questão 2e.

2d. Nos dias que você pedala quanto tempo no total você pedala POR DIA para ir de um lugar para outro? horas minutos

2e. Em quantos dias da ultima semana você caminhou por pelo menos 10 minutos contínuos para ir de um lugar para outro? (NÃO inclua as caminhadas por lazer ou exercício) dias por SEMANA ( ) Nenhum - Vá para a Secão 3.

2f. Quando você caminha para ir de um lugar para outro quanto tempo POR DIA você gasta? (NÃO inclua as caminhadas por lazer ou exercício) horas _ minutos

\section{SEÇÃO 3 - ATIVIDADE FÍSICA EM CASA: TRABALHO, TAREFAS DOMÉSTICAS E CUIDAR} DA FAMÍLIA.

Esta parte inclui as atividades físicas que você fez na ultima semana na sua casa e ao redor da sua casa, por exemplo, trabalho em casa, cuidar do jardim, cuidar do quintal, trabalho de manutenção da casa ou para cuidar da sua família. Novamente pense somente naquelas atividades físicas que você faz por pelo menos 10 minutos contínuos.

3a. Em quantos dias da ultima semana você fez atividades moderadas por pelo menos 10 minutos como carregar pesos leves, limpar vidros, varrer, rastelar no jardim ou quintal. dias por SEMANA ( ) Nenhum - Vá para questão 3b.

3b. Nos dias que você faz este tipo de atividades quanto tempo no total você gasta POR DIA fazendo essas atividades moderadas no jardim ou no quintal? horas __ minutos

3c. Em quantos dias da ultima semana você fez atividades moderadas por pelo menos 10 minutos como carregar pesos leves, limpar vidros, varrer ou limpar o chão dentro da sua casa. dias por SEMANA ( ) Nenhum - Vá para questão 3d.

3d. Nos dias que você faz este tipo de atividades moderadas dentro da sua casa quanto tempo no total você gasta POR DIA? horas minutos

3e. Em quantos dias da ultima semana você fez atividades físicas vigorosas no jardim ou quintal por pelo menos 10 minutos como carpir, lavar o quintal, esfregar o chão: dias por SEMANA （ ） Nenhum - Vá para a secão 4.

3f. Nos dias que você faz este tipo de atividades vigorosas no quintal ou jardim quanto tempo no total você gasta POR DIA? horas minutos

SEÇÃO 4- ATIVIDADES FÍSICAS DE RECREAÇÃO, ESPORTE, EXERCÍCIO E DE LAZER.

Esta seção se refere às atividades físicas que você fez na ultima semana unicamente por recreação, esporte, exercício ou lazer. Novamente pense somente nas atividades físicas que faz por pelo menos 10 minutos contínuos. Por favor, NÃO inclua atividades que você já tenha citado.

4a. Sem contar qualquer caminhada que você tenha citado anteriormente, em quantos dias da ultima semana você caminhou por pelo menos 10 minutos contínuos no seu tempo livre? dias por SEMANA ( ) Nenhum - Vá para questão 4b

4b. Nos dias em que você caminha no seu tempo livre, quanto tempo no total você gasta POR 
DIA?

horas minutos

4c. Em quantos dias da ultima semana você fez atividades moderadas no seu tempo livre por pelo menos 10 minutos, como pedalar ou nadar a velocidade regular, jogar bola, vôlei , basquete, tênis : dias por SEMANA

( ) Nenhum - Vá para questão 4d.

4d. Nos dias em que você faz estas atividades moderadas no seu tempo livre quanto tempo no total você gasta POR DIA? horas __ minutos

4e. Em quantos dias da ultima semana você fez atividades vigorosas no seu tempo livre por pelo menos 10 minutos, como correr, fazer aeróbicos, nadar rápido, pedalar rápido ou fazer Jogging: dias por SEMANA

( ) Nenhum - Vá para seção 5.

4f. Nos dias em que você faz estas atividades vigorosas no seu tempo livre quanto tempo no total você gasta POR DIA? horas minutos

\section{SEÇÃO 5 - TEMPO GASTO SENTADO}

Estas últimas questões são sobre o tempo que você permanece sentado todo dia, no trabalho, na escola ou faculdade, em casa e durante seu tempo livre. Isto inclui o tempo sentado estudando, sentado enquanto descansa, fazendo lição de casa visitando um amigo, lendo, sentado ou deitado assistindo TV. Não inclua o tempo gasto sentando durante o transporte em ônibus, trem, metrô ou carro.

5a. Quanto tempo no total você gasta sentado durante um dia de semana? horas ___ minutos

5b. Quanto tempo no total você gasta sentado durante em um dia de final de semana? horas ___ minutos 


\section{ANEXO 4- CLASSIFICAÇÃo DO NÍVEL DE ATIVIDADE FÍSICA IPAQ}

1. MUITO ATIVO: aquele que cumpriu as recomendações de:

a) VIGOROSA: $\geq 5$ dias/sem e $\geq 30$ minutos por sessão

b) VIGOROSA: $\geq 3$ dias/sem e $\geq 20$ minutos por sessão + MODERADA e/ou CAMINHADA: $\geq 5$ dias/sem e $\geq 30$ minutos por sessão.

2. ATIVO: aquele que cumpriu as recomendações de:

a) VIGOROSA: $\geq 3$ dias/sem e $\geq 20$ minutos por sessão; ou

b) MODERADA ou CAMINHADA: $\geq 5$ dias/sem e $\geq 30$ minutos por sessão; ou

c) Qualquer atividade somada: $\geq 5$ dias/sem e $\geq 150$ minutos/sem (caminhada + moderada + vigorosa).

3. IRREGULARMENTE ATIVO: aquele que realiza atividade física, porém, insuficiente para ser classificado como ativo pois, não cumpre as recomendações quanto à freqüência ou duração.

Para realizar essa classificação soma-se a freqüência e a duração dos diferentes tipos de atividades (caminhada + moderada + vigorosa). Este grupo foi dividido em dois subgrupos de acordo com o cumprimento ou não de alguns dos critérios de recomendação:

IRREGULARMENTE ATIVO A: aquele que atinge pelo menos um dos critérios da recomendação quanto à freqüência ou quanto à duração da atividade:

a) Frequiência: 5 dias /semana ou

b) Duração: 150 min / semana

IRREGULARMENTE ATIVO B: aquele que não atingiu nenhum dos critérios da recomendação quanto à freqüência nem quanto à duração.

4. SEDENTÁRIO: aquele que não realizou nenhuma atividade física por pelo menos 10 minutos contínuos durante a semana. 


\section{ANEXO 5-TERMO DE CONSENTIMENTO}

\section{Projeto de pesquisa}

\section{INFLUÊNCIA DA ORIENTAÇÃO ESPACIAL E DA ORGANIZAÇÃO POSTURAL NA LOCOMOÇÃO EM IDOSOS}

- Estas informações estão sendo fornecidas para sua participação voluntária neste estudo, que visa estudar os efeitos da orientação espacial e da organização postural na locomoção em idosos.

- Esta avaliação não trará nenhum desconforto ou risco a sua integridade física.

- A pesquisa será feita utilizando um acelerômetro 3D para observar as variações de deslocamento da trajetória proposta. Nenhuma conduta será invasiva ao seu corpo.

- Em qualquer etapa do estudo, você terá acesso aos profissionais responsáveis pela pesquisa para esclarecimento de eventuais dúvidas. O principal investigador é a pesquisadora Renata Garrido Cosme.

- É garantida a liberdade da retirada de consentimento a qualquer momento e deixar de participar do estudo, sem qualquer prejuízo à sua pessoa;

- As informações obtidas serão analisadas em conjunto com outros voluntários, não sendo divulgado a identificação de nenhum destes;

- Não há despesas pessoais para o participante em qualquer fase do estudo.

- Também não há compensação financeira relacionada à sua participação. Se existir qualquer despesa adicional, como a necessidade de transporte do participante até o local da coleta de dados, ela será absorvida pelo orçamento da pesquisa;

- Os dados coletados serão utilizados exclusivamente para este estudo.

\section{Termo de Consentimento Livre e Esclarecido}

Acredito ter sido suficientemente informado a respeito das informações que li ou que foram lidas para mim, descrevendo o estudo Influência da Orientação Espacial e da Organização Postural na Locomoção em Idosos.

Eu discuti com a aluna de mestrado Renata Garrido Cosme sobre a minha decisão em participar nesse estudo. Ficaram claros para mim quais são os propósitos do estudo, os procedimentos a serem realizados, seus desconfortos e riscos, as garantias de confidencialidade e de esclarecimentos permanentes. Ficou claro também que minha participação é isenta de despesas. Concordo voluntariamente em participar deste estudo e poderei retirar o meu consentimento a qualquer momento, antes ou durante o mesmo, sem penalidades ou prejuízo.

Assinatura do paciente

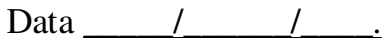
RG:

Assinatura da testemunha

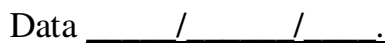
RG:

Declaro que obtive de forma apropriada e voluntária o Consentimento Livre e Esclarecido deste voluntário para a participação neste estudo.

Renata Garrido Cosme

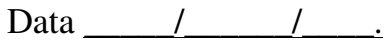

RG: 


\section{ANEXO 6- ESCALA DE EQUILÍBRIO DE BERG} 1) Posição sentada para posição em pé
Instrução: Por favor, levante-se. Tente não usar suas mãos para se
apoiar.
(4) capaz de levantar-se sem utilizar as mãos e estabilizar-se independentemente

(3) capaz de levantar-se independentemente utilizando as mãos

(2) capaz de levantar-se utilizando as mãos após diversas tentativas

(1) necessita de ajuda mínima para levantar-se ou estabilizar-se

(0) necessita de ajuda moderada ou máxima para levantar-se

\author{
2) Permanecer em pé sem apoio \\ Instrução: Por favor, fique em pé por 2 minutos sem se apoiar \\ Se o paciente for capaz de permanecer em pé por 2 minutos sem \\ apoio, dê o número total de pontos o item $\mathrm{N}^{\circ} 3$. \\ Continue com o item $\mathrm{N}^{\circ} 4$.
}

3) Permanecer sentado sem apoio nas costas, mas com os pés apoiados no chão ou num banquinho

Instrução: Por favor, fique sentado sem apoiar as costas com os braços cruzados por 2 minutos.
(4) capaz de permanecer em pé com segurança por 2 minutos

(3) capaz de permanecer em pé por 2 minutos com supervisão

(2) capaz de permanecer em pé por 30 segundos sem apoio

(1) necessita de várias tentativas para permanecer em pé por 30 segundos sem apoio

(0) incapaz de permanecer em pé por 30 segundos sem apoio
4) Posição em pé para posição sentada

Instrução: Por favor, sente-se.
(4) capaz de permanecer sentado com segurança e com firmeza por 2 minutos

(3) capaz de permanecer sentado por 2 minutos sob supervisão

(2) capaz de permanecer sentado por 30 segundos

(1) capaz de permanecer sentado por 10 segundos

(0) incapaz de permanecer sentado sem apoio durante 10 segundos

\section{(4) senta-se com segurança com uso mínimo das mãos}

(3) controla a descida utilizando as mãos

(2) utiliza a parte posterior das pernas contra a cadeira para controlar a descida

(1) senta-se independentemente, mas tem descida sem controle

(0) necessita de ajuda para sentar-se

5) Transferências
Instrução: Arrume as cadeiras perpendicularmente ou uma de
frente para a outra para uma transferência em pivô. Peça
ao paciente para transferir-se de uma cadeira com apoio de braço
para uma cadeira sem apoio de braço, e vice-versa.
6) Permanecer em pé sem apoio com os olhos fechados
Instrução: Por favor, fique em pé e feche os olhos por 10 segun-
dos.

(4) capaz de transferir-se com segurança com uso mínimo das mãos

(3) capaz de transferir-se com segurança com o uso das mãos

(2) capaz de transferir-se seguindo orientações verbais e/ou supervisão

(1) necessita de uma pessoa para ajudar

(0) necessita de duas pessoas para ajudar ou supervisionar para realizar a tarefa com segurança dos

(4) capaz de permanecer em pé por 10 segundos com segurança

(3) capaz de permanecer em pé por 10 segundos com supervisão

(2) capaz de permanecer em pé por 3 segundos

(1) incapaz de permanecer com os olhos fechados durante 3 segundos, mas mantém-se em pé

(0) necessita de ajuda para não cair

7) Permanecer em pé sem apoio com os pés juntos Instrução: Junte seus pés e fique em pé sem se apoiar.
(4) capaz de posicionar os pés juntos independentemente e permanecer por 1 minuto com segurança

(3) capaz de posicionar os pés juntos independentemente e permanecer por 1 minuto com supervisão

(2) capaz de posicionar os pés juntos independentemente e permanecer por 30 segundos

(1) necessita de ajuda para posicionar-se, mas é capaz de permanecer com os pés juntos durante 15 segundos

(0) necessita de ajuda para posicionar-se e é incapaz de permanecer nessa posição por 15 segundos

(4) pode avançar a frente $>25 \mathrm{~cm}$ com segurança

(3) pode avançar a frente $>12,5 \mathrm{~cm}$ com segurança

(2) pode avançar a frente $>5 \mathrm{~cm}$ com segurança

(1) pode avançar a frente, mas necessita de supervisão

(0) perde o equilíbrio na tentativa, ou necessita de apoio externo
9) Virar-se e olhar para trás por cima dos ombros direito e esquerdo enquanto permanece em pé

Instrução: Vire-se para olhar diretamente atrás de você por cima do seu ombro esquerdo sem tirar os pés do chão. Faça o mesmo por cima do ombro direito.

\section{0) Girar 360 graus}

Instrução: Gire-se completamente ao redor de si mesmo. Pausa Gire-se completamente ao redor de si mesmo em sentido contrário.

\section{enquanto permanece em pé sem apoio}

11) Posicionar os pés alternadamente no degrau ou banquinho

Instrução: Toque cada pé alternadamente no degrau/banquinho.

Continue até que cada pé tenha tocado o degrau/banquinho quatro vezes.

\section{2) Permanecer em pé sem apoio com um pé à frente}

Instrução: Coloque um pé diretamente à frente do outro na mesma linha, se você achar que não irá conseguir, coloque o pé um pouco mais à frente do outro pé e levemente para o lado.
(4) olha para trás de ambos os lados com uma boa distribuição do peso

(3) olha para trás somente de um lado, o lado contrário demonstra menor distribuição do peso

(2) vira somente para os lados, mas mantém o equilibrio

(1) necessita de supervisão para virar

(0) necessita de ajuda para não perder o equilíbrio ou cai
(4) capaz de girar 360 graus com segurança em 4 segundos ou menos

(3) capaz de girar 360 graus com segurança somente para um lado em 4 segundos ou menos

(2) capaz de girar 360 graus com segurança, mas lentamente

(1) necessita de supervisão próxima ou orientações verbais

(0) necessita de ajuda enquanto gira

(4) capaz de permanecer em pé independentemente e com segurança, completando 8 movimentos em 20 segundos

(3) capaz de permanecer em pé independentemente e completar 8 movimentos em $>20$ segundos

(2) capaz de completar 4 movimentos sem ajuda

(1) capaz de completar $>2$ movimentos com o mínimo de ajuda

(0) incapaz de tentar, ou necessita de ajuda para não cair

(4) capaz de colocar um pé imediatamente à frente do outro, independentemente, e permanecer por 30 segundos

(3) capaz de colocar um pé um pouco mais à frente do outro e levemente para o lado, independentemente, e permanecer por 30 segundos

(2) capaz de dar um pequeno passo, independentemente, e permanecer por 30 segundos

(1) necessita de ajuda para dar o passo, porém permanece por 15 segundos

(0) perde o equilíbrio ao tentar dar um passo ou ficar de pé

13) Permanecer em pé sobre uma perna

Instrução: Fique em pé sobre uma perna o máximo que você pu-

(4) capaz de levantar uma perna independentemente e permanecer por $>10$ segundos

(3) capaz de levantar uma perna independentemente e permanecer por 5-10 segundos

(2) capaz de levantar uma perna independentemente e permanecer por $\geq 3$ segundos

(1) tenta levantar uma perna, mas é incapaz de permanecer por 3 segundos, embora permaneça em pé inç్fĐendentemente

(0) incapaz de tentar, ou necessita de ajuda para não cair 


\section{ANEXO 7- TESTE DE EQUILÍBRIO DE TINETTI}

Instruções: Sujeito sentado em uma cadeira rígida, sem braços

\begin{tabular}{|c|c|}
\hline 1) Equilíbrio sentado: & $\begin{array}{l}\text { (0) Inclina-se ou desliza na cadeira } \\
\text { (1) Estável, seguro }\end{array}$ \\
\hline 2) Levanta-se da cadeira: & $\begin{array}{l}\text { (0) Incapaz sem ajuda } \\
\text { (1) Capaz, usa membros superiores para auxiliar } \\
\text { (2) Capaz sem usar membros superiores }\end{array}$ \\
\hline 3) Tentativas para se levantar: & $\begin{array}{l}\text { (0) Incapaz sem ajuda } \\
\text { (1) Capaz, requer mais de uma tentativa } \\
\text { (2) Capaz de se levantar, uma tentativa }\end{array}$ \\
\hline $\begin{array}{l}\text { 4) Equilíbrio de pé imediato } \\
\text { (primeiros } 5 \text { segundos): }\end{array}$ & $\begin{array}{l}\text { (0) Instável (cambaleia, move os pés, oscila o tronco) } \\
\text { (1) Estável, mas usa dispositivo de auxílio à marcha } \\
\text { (2) Estável sem dispositivo de auxílio }\end{array}$ \\
\hline 5) Equilíbrio de pé: & $\begin{array}{l}\text { (0) Instável } \\
\text { (1) Instável, mas aumenta a base de suporte (entre os calcanhares }>10 \mathrm{~cm} \text { de afastamento) e usa dispositivo de auxílio } \\
\text { (2) Diminuição da base sem dispositivo de auxílio }\end{array}$ \\
\hline $\begin{array}{l}\text { 6) Desequilíbrio no esterno (sujeito na posição de pé com } \\
\text { os pés o mais próximo possível, o examinador empurra } \\
\text { suavemente o sujeito na altura do esterno com a palma da } \\
\text { mão } 3 \text { vezes seguidas: }\end{array}$ & $\begin{array}{l}\text { (0) Começa a cair } \\
\text { (1) Cambelaia, se agarra e se segura em si mesmo } \\
\text { (2) Estável }\end{array}$ \\
\hline 7) Olhos fechados: & $\begin{array}{l}\text { (0) Instável } \\
\text { (1) Estável }\end{array}$ \\
\hline 8) Girar $360^{\circ}$ : & $\begin{array}{l}\text { (0) Instabilidade (se agarra, cambaleia) } \\
\text { (1) Passos descontinuados } \\
\text { (2) Continuidade }\end{array}$ \\
\hline 9) Sentar-se: & $\begin{array}{l}\text { (0) Inseguro (não avalia bem a distância, cai na cadeira) } \\
\text { (1) Usa os braços ou não tem movimentos suaves } \\
\text { (2) Seguro, movimentos suave }\end{array}$ \\
\hline Escore de equilíbrio: & $/ 16$ \\
\hline
\end{tabular}




\section{ANEXO 8 - TESTE DE MARCHA DE TINETTI}

Instruções: Sujeito de pé com o examinador, caminha num corredor ou na sala, primeiro no seu ritmo usual e, em seguida, rápido, porém muito seguro, com os dispositivos de auxílio à marcha usuais:

\begin{tabular}{|c|c|}
\hline $\begin{array}{l}\text { 1) Iniciação da } \\
\text { marcha: }\end{array}$ & $\begin{array}{l}\text { (0) Imediato e após o comando Vá (qualquer hesitação ou múltiplas tentativas para iniciar) } \\
\text { (1) Sem hesitação }\end{array}$ \\
\hline $\begin{array}{l}\text { 2) Comprimento } \mathrm{e} \\
\text { altura do passo: }\end{array}$ & $\begin{array}{l}\text { a) Perna Dem balanceio: } \\
\text { (0) Não passa o membro E } \\
\text { (1) Passa o membro E } \\
\text { (0) Pé D não se afasta completamente do solo com o passo } \\
\text { (1) Pé D se afasta completamente do solo } \\
\text { b) Perna E em balanceio } \\
\text { (0) Não passa o membro D } \\
\text { (1) Passa o membro D } \\
\text { (0) Pé E não se afasta completamente do solo com o passo } \\
\text { (1) Pé E se afasta completamente do solo }\end{array}$ \\
\hline 3) Simetria do passo: & $\begin{array}{l}\text { (0) Passos D e E desiguais } \\
\text { (1) Passos D e E parecem iguais }\end{array}$ \\
\hline $\begin{array}{l}\text { 4) Continuidade do } \\
\text { passo: }\end{array}$ & $\begin{array}{l}\text { (0) Parada ou descontinuidade entre os passos } \\
\text { (1) Passos parecem contínuos }\end{array}$ \\
\hline $\begin{array}{l}\text { 5) Desvio da linha reta } \\
\text { (distância aproximada } \\
\text { de } 3 \mathrm{~m} \mathrm{X} 30 \mathrm{~cm} \text { ): }\end{array}$ & $\begin{array}{l}\text { (0) Desvio marcado } \\
\text { (1) Desvio leve e moderado ou usa dispositivo de auxílio à marcha } \\
\text { (2) Caminha em linha reta sem dispositivo de auxílio }\end{array}$ \\
\hline 6) Tronco: & $\begin{array}{l}\text { (0) Oscilação marcada ou usa dispositivo de auxílio à marcha } \\
\text { (1) Sem oscilação, mas com flexão de joelhos ou dor lombar ou afasta os braços enquanto anda } \\
\text { (2) Sem oscilação, sem flexão, sem uso dos braços ou de dispositivo de auxílio à marcha }\end{array}$ \\
\hline 7)Base de apoio: & $\begin{array}{l}\text { (0) Calcanhares afastados } \\
\text { (1) Calcanhares quase se tocando durante a marcha }\end{array}$ \\
\hline Escore de Marcha: & $\ldots$ \\
\hline
\end{tabular}




\section{ANEXO 9 - ROTINA PARA CÁLCULO DO DFA E RANDOM WALK 1}

function output1=DFA(DATA, win_length, order)






\section{ANEXO 10 - ROTINA PARA O CÁLCULO DO DFA E RANDOM WALK 2}

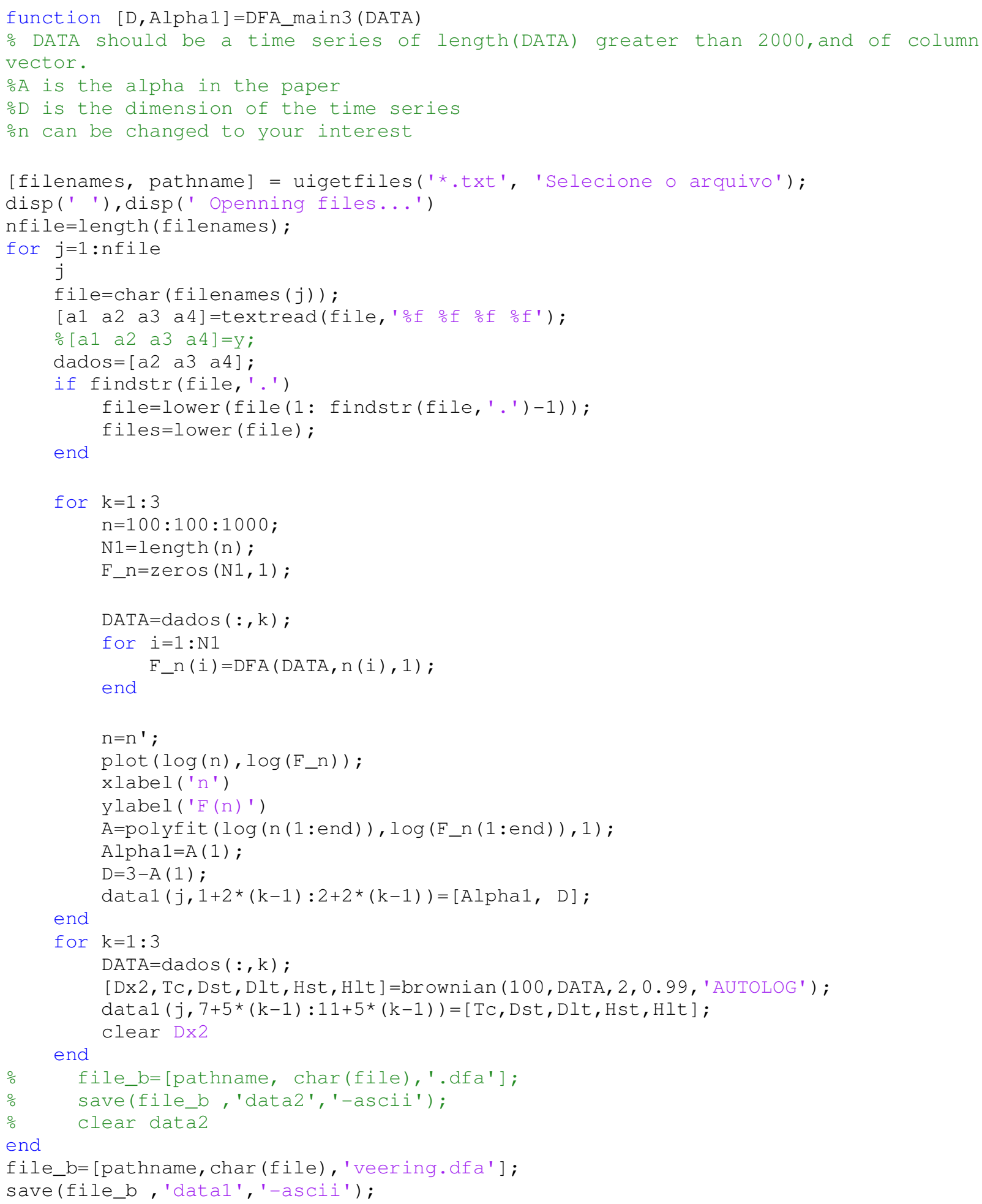

